\title{
Targeting the Lactate Transporter MCT1 in Endothelial Cells Inhibits Lactate-Induced HIF-1 Activation and Tumor Angiogenesis
}

\author{
Pierre Sonveaux ${ }^{1,2_{*}^{*}}$, Tamara Copetti ${ }^{1}$, Christophe J. De Saedeleer ${ }^{1}$, Frédérique Végran ${ }^{1}$, Julien Verrax ${ }^{1}$, \\ Kelly M. Kennedy ${ }^{2}$, Eui Jung Moon ${ }^{4}$, Suveera Dhup ${ }^{1}$, Pierre Danhier ${ }^{3}$, Françoise Frérart ${ }^{1}$, Bernard Gallez ${ }^{3}$, \\ Anthony Ribeiro ${ }^{5}$, Carine Michiels ${ }^{6}$, Mark W. Dewhirst ${ }^{2,49}$, Olivier Feron ${ }^{19}$ \\ 1 Pole of Pharmacology, Institute of Experimental and Clinical Research (IREC), Université catholique de Louvain (UCL), Brussels, Belgium, 2 Department of Radiation \\ Oncology, Duke University Medical Center, Durham, North Carolina, United States of America, 3 Nuclear Magnetic Resonance Research Group, Louvain Drug Research \\ Institute (LDRI), Université catholique de Louvain (UCL), Brussels, Belgium, 4 Department of Pathology, Duke University Medical Center, Durham, North Carolina, United \\ States of America, $\mathbf{5}$ Department of Radiology and Biochemistry, Duke University Medical Center, Durham, North Carolina, United States of America, $\mathbf{6}$ Laboratory of \\ Biochemistry and Cellular Biology, University of Namur (FUNDP), Namur, Belgium
}

\begin{abstract}
Switching to a glycolytic metabolism is a rapid adaptation of tumor cells to hypoxia. Although this metabolic conversion may primarily represent a rescue pathway to meet the bioenergetic and biosynthetic demands of proliferating tumor cells, it also creates a gradient of lactate that mirrors the gradient of oxygen in tumors. More than a metabolic waste, the lactate anion is known to participate to cancer aggressiveness, in part through activation of the hypoxia-inducible factor-1 (HIF-1) pathway in tumor cells. Whether lactate may also directly favor HIF-1 activation in endothelial cells (ECs) thereby offering a new druggable option to block angiogenesis is however an unanswered question. In this study, we therefore focused on the role in ECs of monocarboxylate transporter 1 (MCT1) that we previously identified to be the main facilitator of lactate uptake in cancer cells. We found that blockade of lactate influx into ECs led to inhibition of HIF-1-dependent angiogenesis. Our demonstration is based on the unprecedented characterization of lactate-induced HIF-1 activation in normoxic ECs and the consecutive increase in vascular endothelial growth factor receptor 2 (VEGFR2) and basic fibroblast growth factor (bFGF) expression. Furthermore, using a variety of functional assays including endothelial cell migration and tubulogenesis together with in vivo imaging of tumor angiogenesis through intravital microscopy and immunohistochemistry, we documented that MCT1 blockers could act as bona fide HIF-1 inhibitors leading to anti-angiogenic effects. Together with the previous demonstration of MCT1 being a key regulator of lactate exchange between tumor cells, the current study identifies MCT1 inhibition as a therapeutic modality combining antimetabolic and anti-angiogenic activities.
\end{abstract}

Citation: Sonveaux P, Copetti T, De Saedeleer CJ, Végran F, Verrax J, et al. (2012) Targeting the Lactate Transporter MCT1 in Endothelial Cells Inhibits LactateInduced HIF-1 Activation and Tumor Angiogenesis. PLoS ONE 7(3): e33418. doi:10.1371/journal.pone.0033418

Editor: Eric Deutsch, Institut Gustave Roussy, France

Received November 30, 2011; Accepted February 8, 2012; Published March 13, 2012

Copyright: (C) 2012 Sonveaux et al. This is an open-access article distributed under the terms of the Creative Commons Attribution License, which permits unrestricted use, distribution, and reproduction in any medium, provided the original author and source are credited.

Funding: This work was supported by grants from the European Research Council (FP7/2007-2013 European Research Council Independent Researcher Starting Grant No. 243188 TUMETABO to P. Sonveaux), the NIH/NCI (CA40355-24 and CA40355-25 to M.W. Dewhirst), the Fonds National de la Recherche Scientifique (F.R.S.-FNRS), an Action de Recherche Concertée from the Communauté Française de Belgique (to P. Sonveaux and O. Feron), the NEOANGIO research program from the Région Wallonne de Belgique (to O. Feron), the Fondation Belge contre le Cancer (200-2008 to P. Sonveaux and O. Feron), and the J. Maisin and St. Luc Foundations (to O. Feron). O. Feron is a Research Director, P. Sonveaux and B. F. Jordan are Research Associates, J. Verrax is a Postdoctoral Researcher, and P. Danhier is a Research Fellow of the F.R.S.-FNRS. C. De Saedeleer is a Télévie Research Fellow. For this study, P. Sonveaux was also supported by a fellowship from the Belgian American Educational Foundation (BAEF). The funders had no role in study design, data collection and analysis, decision to publish, or preparation of the manuscript.

Competing Interests: The authors have declared that no competing interests exist.

*E-mail: pierre.sonveaux@uclouvain.be

9 These authors contributed equally to this work.

\section{Introduction}

Solid tumors most often exhaust their oxygen supply creating tumor hypoxia [1]. Hypoxia initially triggers a key metabolic adaptation, the glycolytic switch, during which glycolysis is uncoupled from the TCA cycle and becomes the primary source of ATP production. This process is extremely fast as it initially proceeds through inhibition of the Pasteur effect, a negative feedback exerted by energy metabolites on the glycolytic flux [2]. Glycolysis is rather inefficient at producing energy, yielding only 2 ATP molecules per molecule of glucose whereas full glucose oxidation provides up to 38 ATP. Further adaptations are thus needed to support cell survival and proliferation under sustained (or repeated episodes of) hypoxia. Two main biological paths have evolved. On the one hand, tumor cells exhibit an accelerated glycolytic flux to meet their high bioenergetic and biosynthetic demands independently of oxygen but at the cost of high glucose consumption and lactate release [3-5]. On the other hand, the angiogenic switch, corresponding to the initiation of vascular extension, aims at increasing oxygen and nutrient supply to hypoxic tumor sites [6]. These two adaptations require de novo protein synthesis and share the transcription factor HIF-1 as a master regulator. 
HIF-1 is an $\alpha \beta$-heterodimer: the HIF- $1 \beta$ subunit is constitutively nuclear whereas HIF- $1 \alpha$ is inducible by hypoxia [7]. Regulation of HIF- $1 \alpha$ protein level involves its posttranslational hydroxylation at proline residues 402 and 564 (human sequence) by prolylhydroxylases (PHDs), predominantly PHD2 [8]. PHDs are Fe(II)- and 2oxoglutarate-dependent dioxygenases that have an absolute requirement for molecular oxygen [9]. In oxygenated cells, proline hydroxylations target HIF- $1 \alpha$ to the von Hippel-Lindau protein complex for poly-ubiquitylation followed by proteasome-dependent degradation [10]. Under hypoxia, HIF PHDs are inactivated, HIF$1 \alpha$ escapes proteolytic degradation, migrates to the cell nucleus, and binds to HIF-1 $\beta$ and co-factors to initiate the transcription of target genes. These target genes include glucose transporters, most glycolytic enzymes, the lactate transporter monocarboxylate transporter 4 (MCT4) and key pro-angiogenic effectors such as vascular endothelial growth factor (VEGF) [11,12]. Because HIF-1 promotes both glycolytic energy production and angiogenesis, it is not surprising that increased levels of HIF- $1 \alpha$ are associated with poor cancer prognosis [13,14].

Several pieces of evidence suggest that the glycolytic switch triggers angiogenesis [15]. The most direct coupling is probably exerted by lactate, the end-product of glycolysis. Lactate has been known for many years to promote angiogenesis in wounds. It promotes collagen deposition [16,17] and enhances VEGF production and activity in fibroblasts [18] and macrophages [19]. The underlying mechanism has been proposed to involve lactate oxidation to pyruvate, together with a decrease in $\mathrm{NAD}^{+}$ and a subsequent decrease in protein poly-ADP-ribosylation [1720]. In glioma tumor cells, lactate was further shown to trigger HIF-1 activation in a hypoxia-independent manner through inhibition of HIF- $1 \alpha$ proline hydroxylations $[21,22]$, resulting in increased VEGF production by tumor cells.

A direct impact of lactate on HIF- $1 \alpha$ expression in endothelial cells has however not been documented. We recently reported that lactate could stimulate nuclear factor-kappa B (NF- $\mathrm{KB})$ activation and interleukin-8 (IL-8) production in ECs [23], proving that these cells could act as a lactate signaling platform continuously fueled by the elevated lactate concentration $(1-40 \mathrm{mM})$ present in the tumor microenvironment [24]. In this study, we report that lactate stimulates HIF-1 activity in ECs, which directly accounts for angiogenesis independently of any additional pro-angiogenic stimulus. We further identify the lactate transporter monocarboxylate transporter 1 (MCT1) as the main regulator of HIF-1 activation by lactate in ECs, and provide unprecedented evidence that HIF-1 inhibition and the associated blockade of angiogenesis may be obtained through MCT1 inhibition.

\section{Results}

\section{ECs take up exogenous lactate}

Confluent ECs were exposed to $10 \mathrm{mM}$ sodium L-lactate, a concentration that corresponds to the level of lactate most commonly detected in human tumors [25]. ${ }^{13}$ C-lactate (methyllabeled) was used in nuclear magnetic resonance (NMR) experiments. ${ }^{13} \mathrm{C}$ NMR spectra of cell lysate collected 6-h after treatment showed a peak at 19 ppm corresponding to intracellular ${ }^{13} \mathrm{C}$-lactate (Figure 1A). In the same conditions, ${ }^{1} \mathrm{H}$ NMR spectra showed doublets arising from intracellular ${ }^{13} \mathrm{C}$-lactate at 1.56 and $1.30 \mathrm{ppm}$, thus confirming that ECs import exogenous lactate (Figure 1B). The uptake rate was quantified in an enzymatic assay specific for $L$-Lactate. Kinetic analyses revealed a time-dependent increase in intracellular lactate after exposure to $10 \mathrm{mM}$ extracellular lactate (Figure 1C).

\section{Exogenous lactate activates HIF-1 in normoxic ECs}

Lactate is known to fuel oxidative phosphorylation in tumor cells and favors cell proliferation even in the absence of an exogenous source of serum or growth factors [26]. In similar serum-free conditions, however, lactate cannot rescue glucosedeprived ECs as documented by an accelerated increase in cell death (Figure S1A). In the presence of glucose, it did not modulate the oxygen consumption rate (Figure S1B). In the following experiments, we therefore examined the signaling effects of lactate added to the growth medium of ECs and we focused on HIF-1, based on previous reports in tumor cells $[21,22]$. Using a dual luciferase reporter assay in normoxic ECs, we found increased HIF-1 activity after a 24-h treatment with $10 \mathrm{mM}$ lactate (Figure 2A). Consistent with HIF-1 activation, we evidenced the nuclear translocation of HIF-1 $\alpha$ (Figure S2). VEGF and basic fibroblast growth factor (bFGF) are major pro-angiogenic agents [27]. VEGF-A is encoded by a HIF-1 target gene [28] while bFGF expression is indirectly induced by HIF-1 [29]. To further investigate HIF-1 activation by lactate, we probed changes in VEGF-A and bFGF release in the supernatant of confluent human umbilical vein endothelial cells (HUVECs) using ELISA. VEGF-A levels were unchanged (Figure 2B) but a 3-fold increase in bFGF secretion was detected after a 24-h incubation with $10 \mathrm{mM}$ lactate (Figure 2C). The same treatment significantly increased the protein expression of VEGF receptor-2 (VEGFR2/flk-1) (Figure 2D), the major transducer of VEGF-mediated angiogenesis in EGs [27]. Increased membrane VEGFR2 expression was confirmed using specific immunostaining in HUVECs (Figure S3A). PCR arrays further revealed that lactate upregulated the transcription of 31 genes in HUVEGs by at least $\sim 2$-fold, of which 10 are known to be direct HIF-1 target genes (Table S1).

HIF-1 activity primarily depends on the stable expression of its $\alpha$ subunit [7]. In normoxic HUVEGs, lactate $(10 \mathrm{mM})$ induced a significant increase in HIF-1 $\alpha$ protein expression 24-h after treatment (Figure 3A). Similar induction was observed in bovine aortic ECs (BAECs) (Figure 3B). Induction of HIF- $1 \alpha$ by lactate was concentration-dependent with a plateau corresponding to a 3fold increase in HIF- $1 \alpha$ protein expression reached after a $24-\mathrm{h}$ exposure to lactate concentrations $\geq 10 \mathrm{mM}$ (Figure 3C). It was also time-dependent with a 5-fold induction peak at 3-h followed by a slow decrease (Figure 3D).

The canonical regulation of HIF-1 activity involves the posttranslational hydroxylation of HIF- $1 \alpha$ on 2 proline residues, a reaction catalyzed by HIF PHDs that promotes HIF- $1 \alpha$ degradation [8]. Our observations that lactate did not significantly alter HIF- $1 \alpha$ transcription (Figure $4 \mathrm{~A}$ ) and still induced HIF- $1 \alpha$ protein expression in the presence of the transcription inhibitor Actinomycin D (Figure 4B) prompted us to check whether lactate could interfere with the PHD reaction. Considering that PHD activity requires 2-oxoglutarate as a substrate and may therefore be influenced by other carboxylates [21-23], we designed competition experiments between lactate and 2-oxoglutarate in normoxic ECs. Addition of 2-oxoglutarate to ECs concentrationdependently reduced the abundance of HIF- $1 \alpha$ in ECs exposed to lactate (Figure 4C; a representative blot is shown in Figure S4A). We also used an ODD-Luc construct to detect PHD activity [30] and showed that $10 \mathrm{mM}$ lactate triggered ODD-driven luciferase

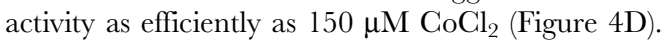

We next aimed to determine whether lactate or pyruvate (resulting from intracellular lactate oxidation) exerted these effects on PHD activity. Pyruvate cannot be detected using NMR. Therefore, we developed an enzymatic assay to show that exposure of ECs to exogenous lactate led to a time-dependent increase in intracellular pyruvate (Figure 4E). Lactate oxidation to 
A

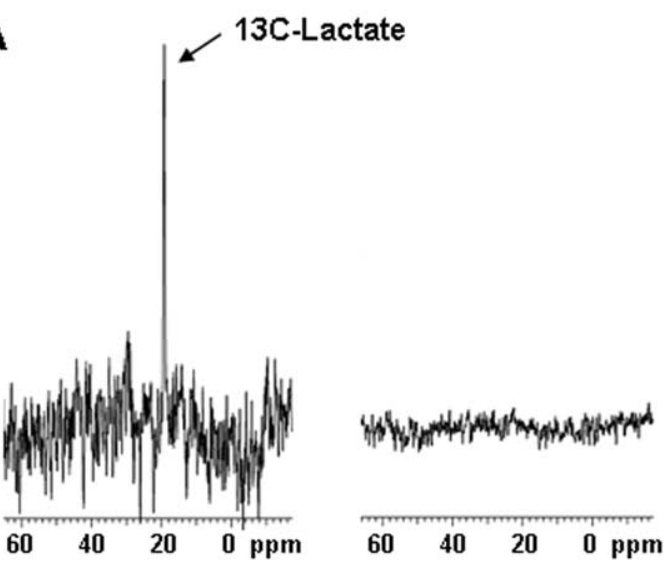

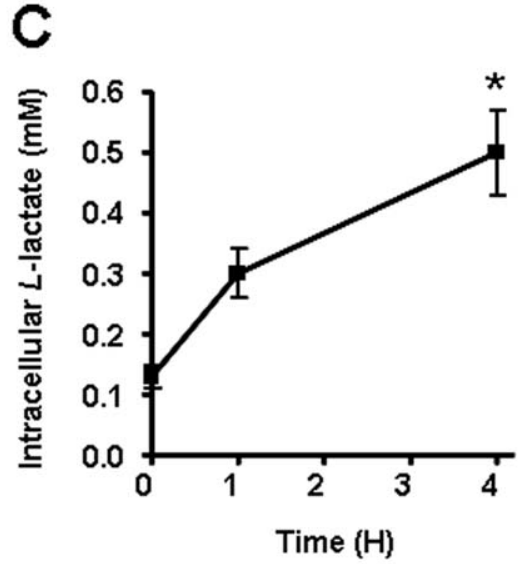

Threonine

12C-Lactate
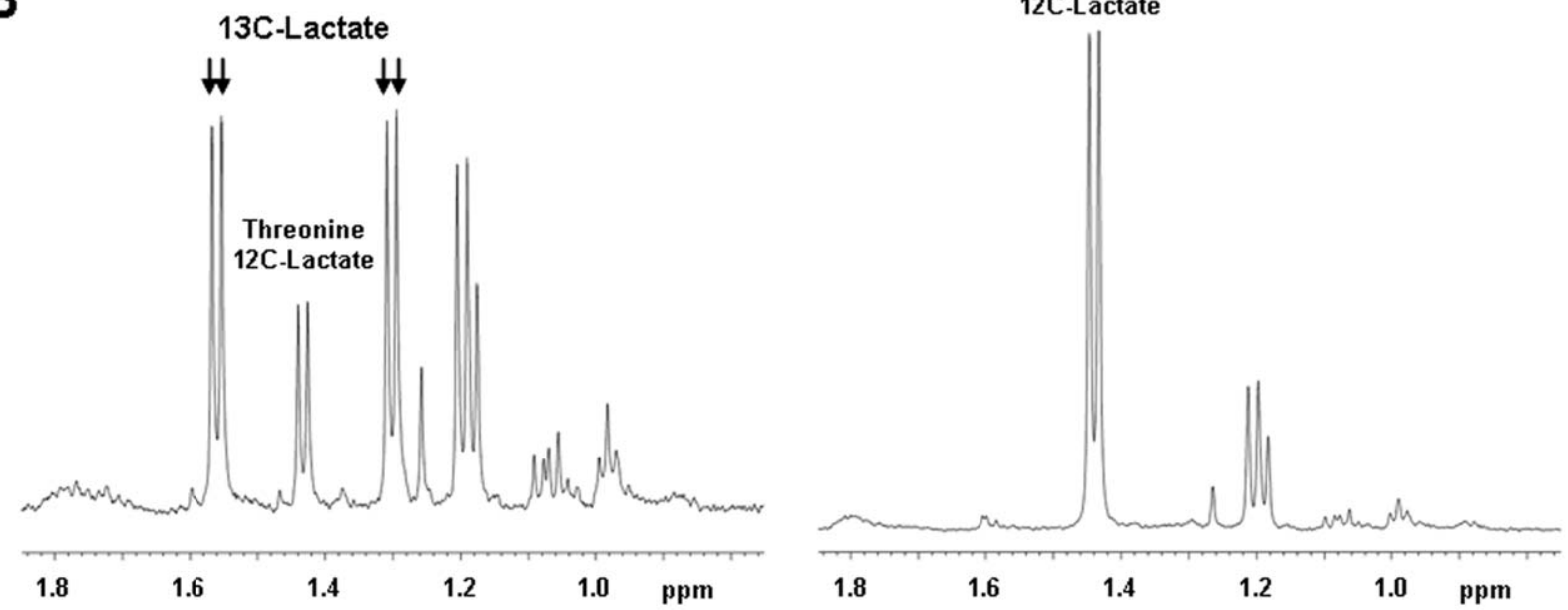

Figure 1. Endothelial cells import exogenous lactate. (A and B) HUVECs were incubated during 6-h with 10 mM of ${ }^{13} \mathrm{C}$-methy-labeled sodium lactate (left panels) or $10 \mathrm{mM}$ of ${ }^{12} \mathrm{C}$ sodium lactate (right panels). ${ }^{13} \mathrm{C}$-lactate was detected using nuclear magnetic resonance (NMR) in cell lysates. (A) In ${ }^{13} \mathrm{C}$ NMR spectra, a ${ }^{13} \mathrm{C}$-Lactate peak is detected at $19 \mathrm{ppm}$. (B) In ${ }^{1} \mathrm{H}$ NMR spectra, the methyl doublets at 1.56 and $1.30 \mathrm{ppm}$ arise from ${ }^{13} \mathrm{C}$ lactate whereas the doublet at $1.43 \mathrm{ppm}$ arises from a coincidental overlap of endogenous ${ }^{12} \mathrm{C}$-Lactate and threonine. (C) HUVECs were incubated with $10 \mathrm{mM}$ sodium $L$-lactate. $L$-Lactate was detected using an enzymatic assay in the lysate of cells collected at different time points. ${ }^{*} p<0.05 ; n=4$. Error bars reflect mean \pm SEM.

doi:10.1371/journal.pone.0033418.g001

pyruvate is preferentially catalyzed by the lactate dehydrogenase-B (LDH-B) gene product. We found that the $\mathrm{LDH}$ competitor oxamate [31] actually blocked lactate-induced HIF- $1 \alpha$ protein expression in normoxic ECs, a property which was not shared by the structurally-related monocarboxylate acetate (Figure $4 \mathrm{~F}$, a representative blot is shown in Figure S4B). Oxamate inhibits both LDH-A and LDH-B. To confirm the involvement of LDH-B, $L D H-B$ was silenced with a specific siRNA (see Figure S5A). This also prevented lactate-induced HIF- $1 \alpha$ expression (Figure $4 \mathrm{G}$ and Figure S4C). Finally, we also provided evidence that pyruvate was a more potent inducer of HIF- $1 \alpha$ than lactate in normoxic ECs (Figure 4H).

\section{Targeting MCT1 blocks lactate-induced HIF-1 activation in normoxic ECs}

The lactate anion can shuttle between extracellular and intracellular compartments through monocarboxylate transporters (MCTs) among which MCT subtypes 1-4 function as passive lactate-proton symporters $[32,33]$. Using quantitative PCR to compare mRNA levels of these 4 transporters, we identified MCT1 as the main transcript in HUVECs (Figure 5A). The corresponding protein was localized at the plasma membrane of the cells, as shown by immunocytochemistry in Figure $5 \mathrm{~B}$ and in Figure S3B where MCT1, its anchor protein basigin/CD147 and the endothelial marker CD31 colocalized. Because MCT1 mediates the uptake of lactate in several cell types [26,32,33], we checked whether MCT1 was involved in lactate signaling in ECs. Silencing MCT1 with a specific siRNA (see Figure S5B for target extinction) prevented HIF- $1 \alpha$ protein stabilization in HUVECs incubated with lactate $(10 \mathrm{mM})$ for $24 \mathrm{~h}$ (Figure $5 \mathrm{C}$ ). Consistent with the involvement of MCT1, $\alpha$-cyano-4-hydroxycinnamate $(\mathrm{CHC})$, a reversible inhibitor that has a 10-fold selectivity for MCT1 compared to other MCTs [34], prevented lactate-induced HIF-1 $\alpha$ protein expression not only in HUVECs (Figure 5D) but also in BAECs (Figure 5E) without showing intrinsic EC toxicity (Figure S6). These results were verified using a series of known MCT1 inhibitors that all successfully blocked lactate-induced HIF-l $\alpha$ protein stabilization in BAEGs (Figure S7). The functional 

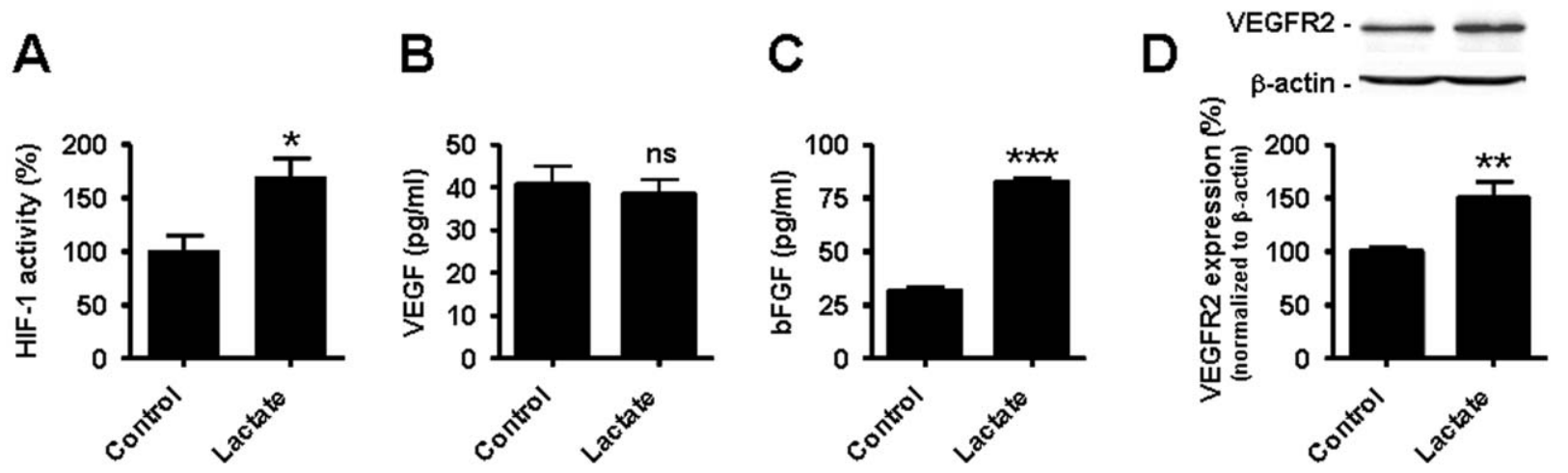

Figure 2. Lactate activates HIF-1 in normoxic endothelial cells. HUVECs were incubated during 24-h with $10 \mathrm{mM}$ lactate or not. (A) The transcriptional activity of HIF-1 was determined using a dual luciferase reporter assay in HUVECs. ${ }^{*} p=0.0207 ; n=4$. (B) VEGF protein level was measured using ELISA in the supernatant of cells. $n s$, non-significant; $n=6$. (C) bFGF protein level was measured using ELISA in the supernatant of cells. ${ }^{* * *} p<0.0001 ; n=5$. (D) VEGFR2 protein expression was detected by western blot in cell lysates. ${ }^{* *} p=0.0084 ; n=4-5$. (A-D) Error bars reflect mean \pm SEM

doi:10.1371/journal.pone.0033418.g002

consequence of MCT1 inhibition was addressed by measuring changes in VEGFR2 expression. CHC blocked lactate-induced upregulation of VEGFR2 protein expression in HUVECs
(Figure 5D) and in BAEGs (Figure 5E). It also reduced basal HIF- $1 \alpha$ and VEGFR2 protein expressions in HUVECs (Figure 5D). We ruled out a major contribution of two known
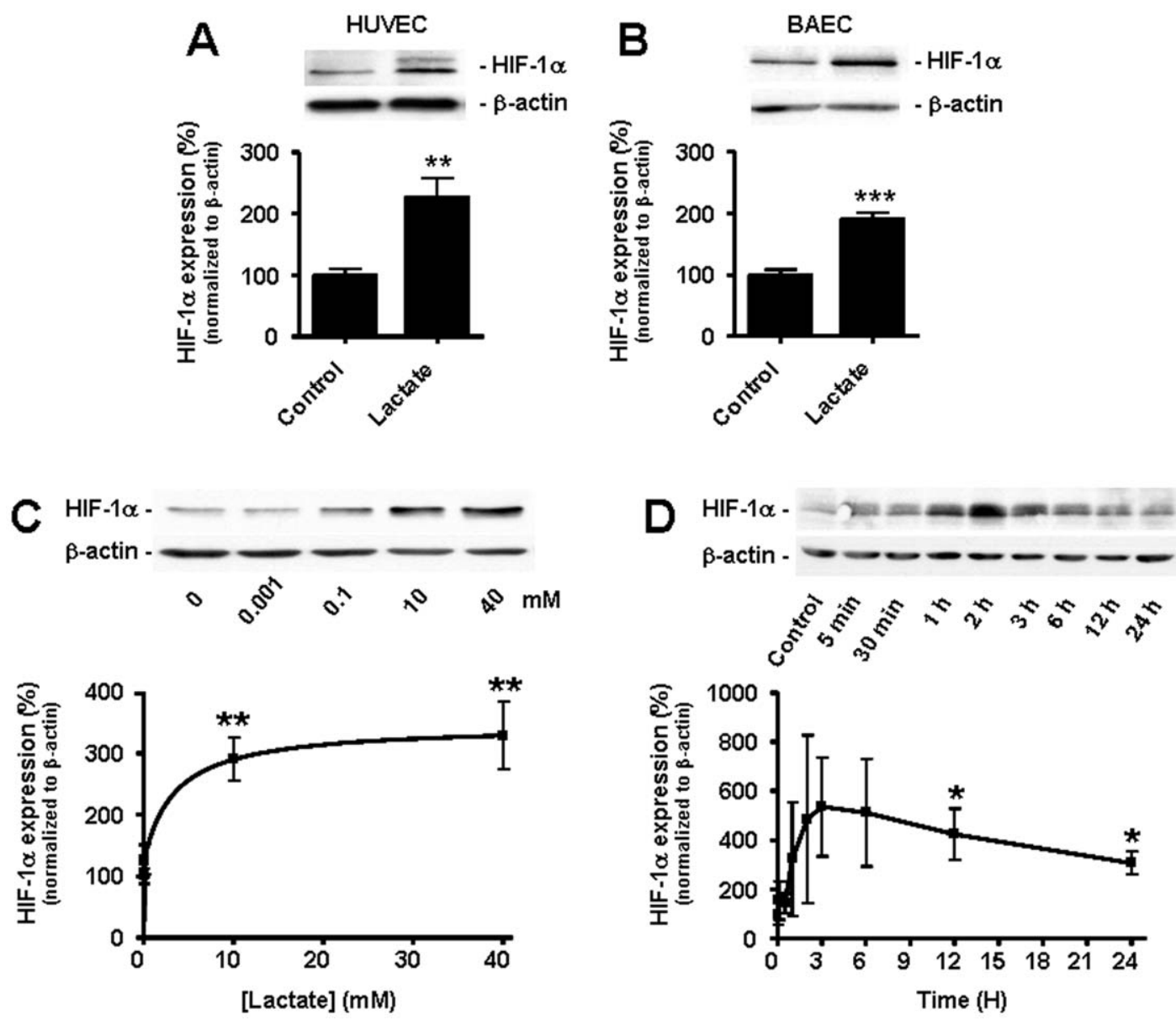

Figure 3. Lactate induces an increase in HIF-1 $\alpha$ protein expression in normoxic endothelial cells. HIF- $1 \alpha$ protein expression was detected by western blot in normoxic ECs. (A) HUVECs were incubated during 24-h with $10 \mathrm{mM}$ lactate or not. ${ }^{* *} p=0.0014 ; n=8$. (B) as in (A) but with BAECs. ${ }^{* * *} p<0.0001 ; n=16-17$. (C) BAECs were incubated during 24 -h with the indicated concentrations of lactate. ${ }^{* *} p<0.01 ; n=4$. (D) BAECs were incubated during the indicated times with $10 \mathrm{mM}$ of lactate. ${ }^{*} p<0.05 ; n=5-12$. (A-D) Error bars reflect mean \pm SEM. doi:10.1371/journal.pone.0033418.g003 

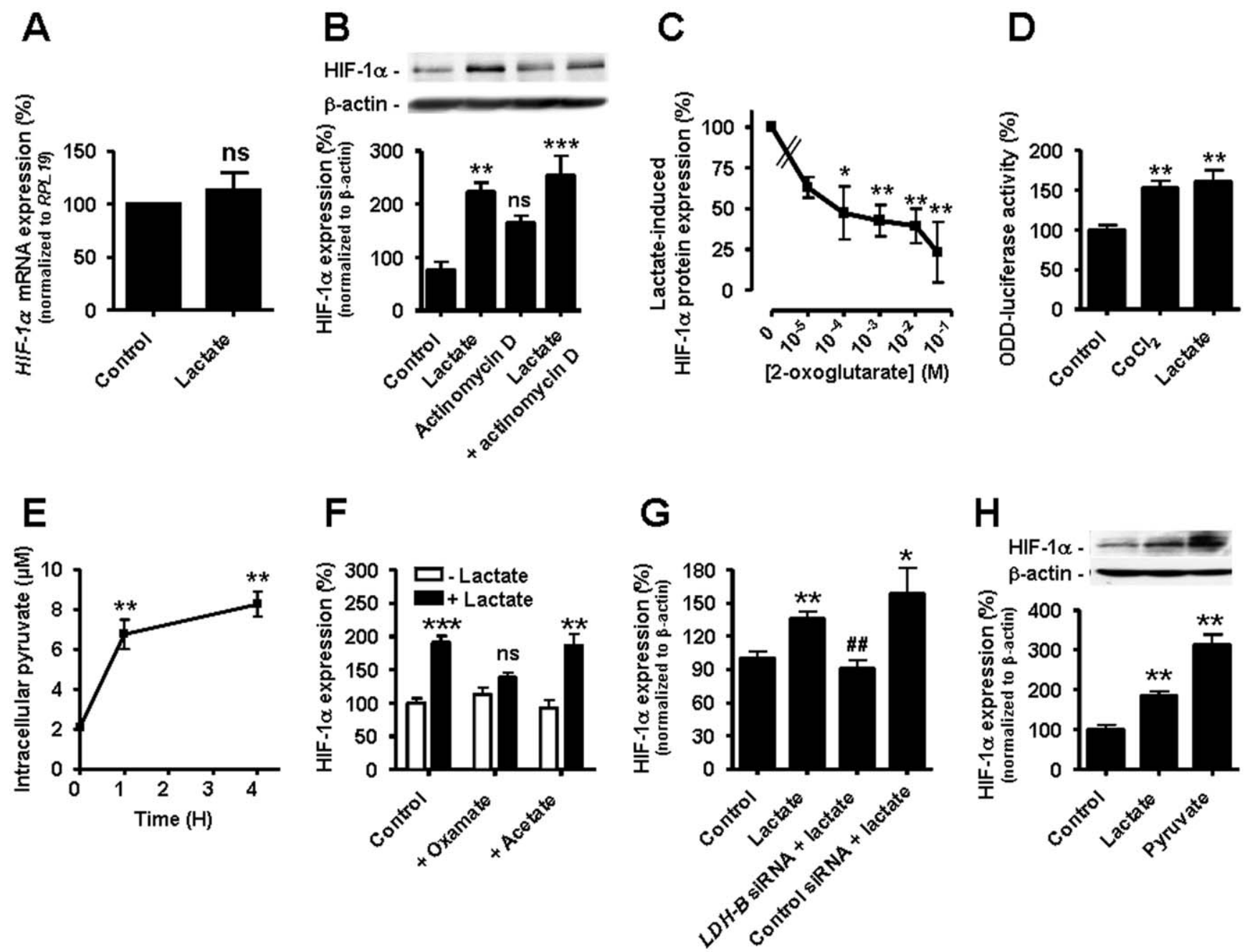

$\mathrm{H}$

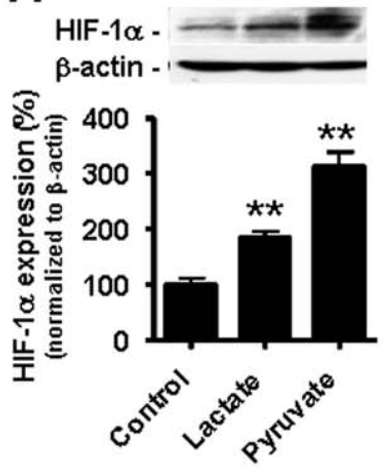

Figure 4. Lactate triggers HIF-1 induction in normoxic endothelial cells. Lactate was used at $10 \mathrm{mM}$ for $24-\mathrm{h}$. (A) HIF-1 $\alpha$ mRNA was detected using qRT-PCR in HUVECs incubated with lactate. $n s$, non-significant; $n=4$. (B and C). HIF-1 $\alpha$ protein expression was detected by western blot in BAECs incubated with lactate and/or (B) $5 \mu \mathrm{g} / \mathrm{ml}$ Actinomycin $\mathrm{D}\left({ }^{* *} p<0.01,{ }^{* *} p<0.005\right.$, ns, non-significant compared to control, $\left.n=3-4\right)$; (C) increasing concentrations of 2-oxoglutarate. ${ }^{*} p<0.05,{ }^{* *} p<0.01 ; n=5-6$. (D) ODD-driven luciferase activity was assessed in HUVECs incubated with $150 \mu \mathrm{M} \mathrm{CoCl} 2$ or lactate. ${ }^{* *} p<0.01 ; n=5$. (E) Intracellular pyruvate was detected using an enzymatic assay in HUVECs incubated with lactate. ${ }^{*} p<0.01 ; n=4$. (F-H) HIF-1 $\alpha$ protein expression was detected by western blot. (F) BAECs were incubated with lactate, oxamate (10 mM), and/or acetate $(10 \mathrm{mM}) .{ }^{* *} p<0.01,{ }^{* * *} p<0.005$, ns, non-significant compared to control cells without lactate; $n=4-16$. (G) HUVECs transfected with the indicated siRNA were incubated with lactate. ${ }^{*} p=0.0170,{ }^{* *} p=0.0019$ compared to control; ${ }^{\# \#} p=0.0056$ compared to lactate alone; $n=3-9$. (H) BAECs were incubated with pyruvate $(10 \mathrm{mM})$, lactate, or not. ${ }^{* *} p<0.01$ compared to control; $n=3-19$. (A-H) Error bars reflect mean \pm SEM. doi:10.1371/journal.pone.0033418.g004

HIF-1 activators, nitric oxide (NO) and reactive oxygen species (ROS) [30], in our experimental conditions. Lactate-driven HIF$1 \alpha$ and VEGFR2 protein expressions were indeed resistant to the NO synthase inhibitor $\mathcal{N}^{\omega}$-nitro- $L$-arginine methyl ester $(\mathrm{L}$ NAME) and to the general antioxidant $\mathcal{N}$-acetyl- $L$-cysteine (NAG) (Figure 5E).

Targeting MCT1 inhibits lactate-induced angiogenesis in tumors

We next investigated whether lactate-induced HIF-1 activation conferred an angiogenic phenotype to ECs. We first observed that lactate increased EC motility, as illustrated by the increased capacity of confluent ECs to colonize a cell-free area in the presence of lactate compared to vehicle (Figure 6A). Lactate-induced migration was quantified in transwell experiments in which ECs in the upper chamber had to invade a layer of Matrigel matrix to reach the bottom well containing lactate. In this assay, $10 \mathrm{mM}$ lactate promoted EC migration as efficiently as $10 \mathrm{ng} / \mathrm{ml}$ VEGF (Figure 6B). EC migration was partly inhibited by CHC, indicating that lactate uptake is as an integral part of the migratory phenotype. The involvement of MCT1 in lactate-induced endothelial invasion was further tested ex vivo. A 3D-culture of aortic rings in collagen gels was used to evaluate the outgrowth of linear endothelial structures from the preexisting vessel [35]. Both basal and lactate-induced endothelial responses were completely blocked by CHC (Figure 6C). The inhibition was sustained but reversible, as sprouting eventually resumed 14 days after the $\mathrm{CHC}$ treatment.

The angiogenic conversion of ECs was also assayed on Matrigel [36]. In this assay, lactate alone promoted sustained endothelial tube formation (Figure 7A), a response that was completely inhibited using SU5402 (targeting VEGF and bFGF receptors), echinomycin (an inhibitor of the transcriptional activity of HIF-1), 

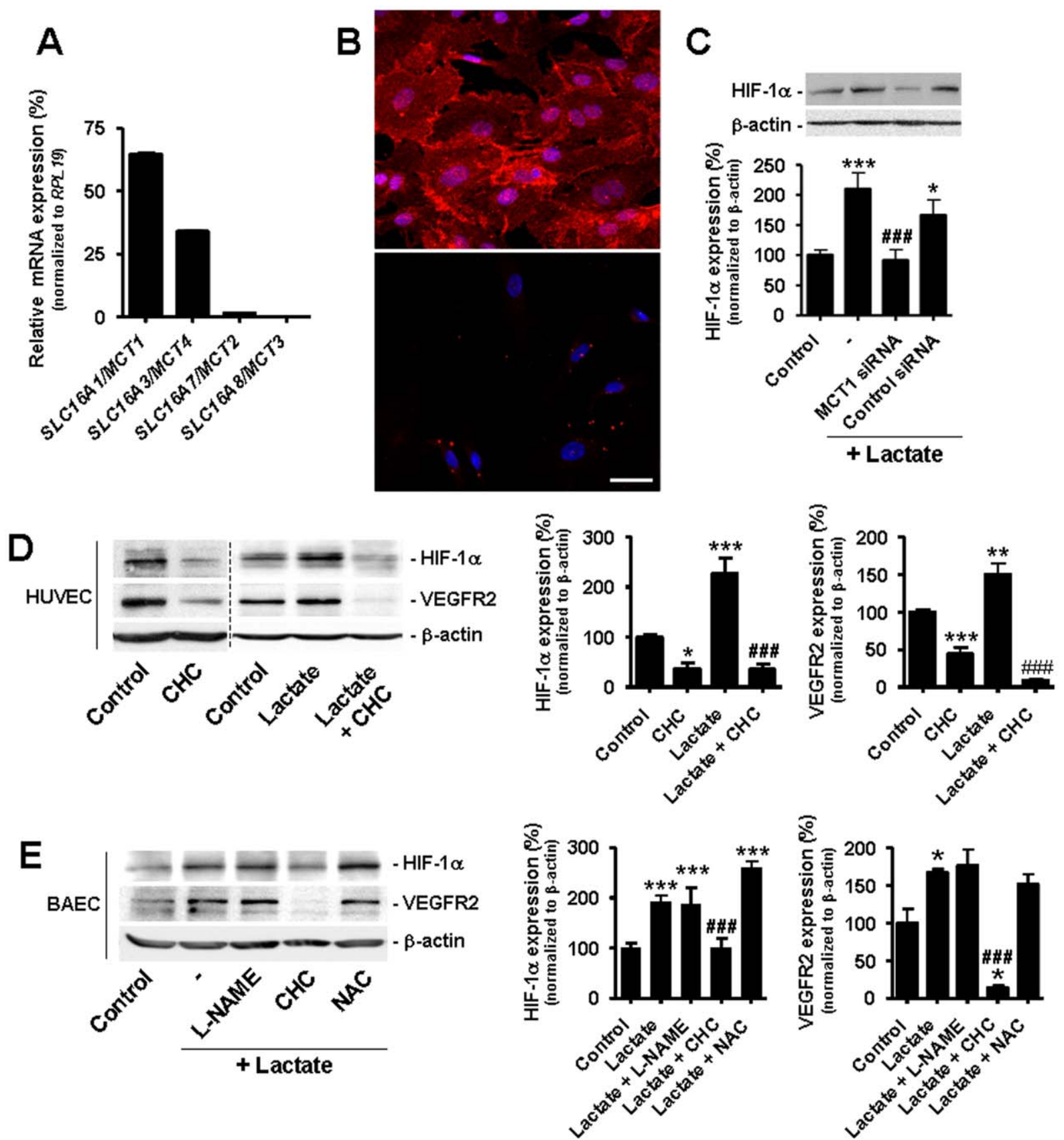

Figure 5. Targeting MCT1 inhibits lactate-induced HIF-1 activation in normoxic endothelial cells. (A) Relative mRNA expression was determined in confluent HUVECs using quantitative RT-PCR. $n=3$. Error bars reflect mean \pm SEM. (B) Immunostaining showing the membrane expression of MCT1 in HUVECs (upper panel) and negative control (lower panel, omission of primary antibody). Bar $=40 \mu \mathrm{m}$. (C) HUVECs transfected with the indicated siRNA were incubated during $24-\mathrm{h}$ with $10 \mathrm{mM}$ lactate or not. HIF-1 $\alpha$ protein expression was detected by western blot. ${ }^{*} p<0.05$, ${ }^{* * *} p<0.005$ compared to control; \#\#\# $p<0.005$ compared lactate alone; $n=6-14$. (D and E) HIF-1 $\alpha$ and VEGFR2 protein expression was detected by western blot. (D) HUVECs were incubated during 24-h with $10 \mathrm{mM}$ lactate and/or $5 \mathrm{mM} \alpha$-cyano-4-hydroxycinnamate (CHC). ${ }^{*} p<0.05,{ }^{* *} p<0.01$, ${ }^{* * *} p<0.005$ compared to control; \#\#\# $p<0.005$ compared to lactate alone; $n=3-12$. (E) BAECs were incubated during $24-\mathrm{h}$ with $10 \mathrm{mM}$ lactate, $5 \mathrm{mM}$ $N^{\omega}{ }^{\omega}$-nitro-L-arginine methyl ester (L-NAME), $5 \mathrm{mM} \alpha$-cyano-4-hydroxycinnamate $(\mathrm{CHC})$, and/or $5 \mathrm{mM} \mathrm{N}$-acetyl-L-cysteine (NAC). ${ }^{*} p<0.01,{ }^{* * *} p<0.005$ compared to control; \#\#\# $p<0.005$ compared to lactate alone; $n=3-14$. (C-E) Error bars reflect mean \pm SEM.

doi:10.1371/journal.pone.0033418.g005

and the MCT1 inhibitor CHC (Figure 7B). Using undiluted Matrigel, we demonstrated that MCT1 silencing with a specific shRNA not only inhibited lactate-induced tubulogenesis but also basal tubulogenesis (Figure S8), suggesting autocrine lactate signaling in cultured ECs.

We performed in vivo experiments to validate lactate as a proangiogenic agent and MCT1 as a new anti-angiogenic target.
First, Matrigel plugs were implanted subcutaneously in each flank of mice, the left plug containing $10 \mathrm{mM}$ lactate and the right plug an equal volume of saline. Seven days later, CD31 immunolabeling of collected plugs revealed a $\sim 10$-fold increase in the endothelial colonization of lactate-containing plugs compared to controls (Figure 8A). Most vascular structures adopted a circular shape and were perfused (Figure 8A, inset), thus confirming lactate 

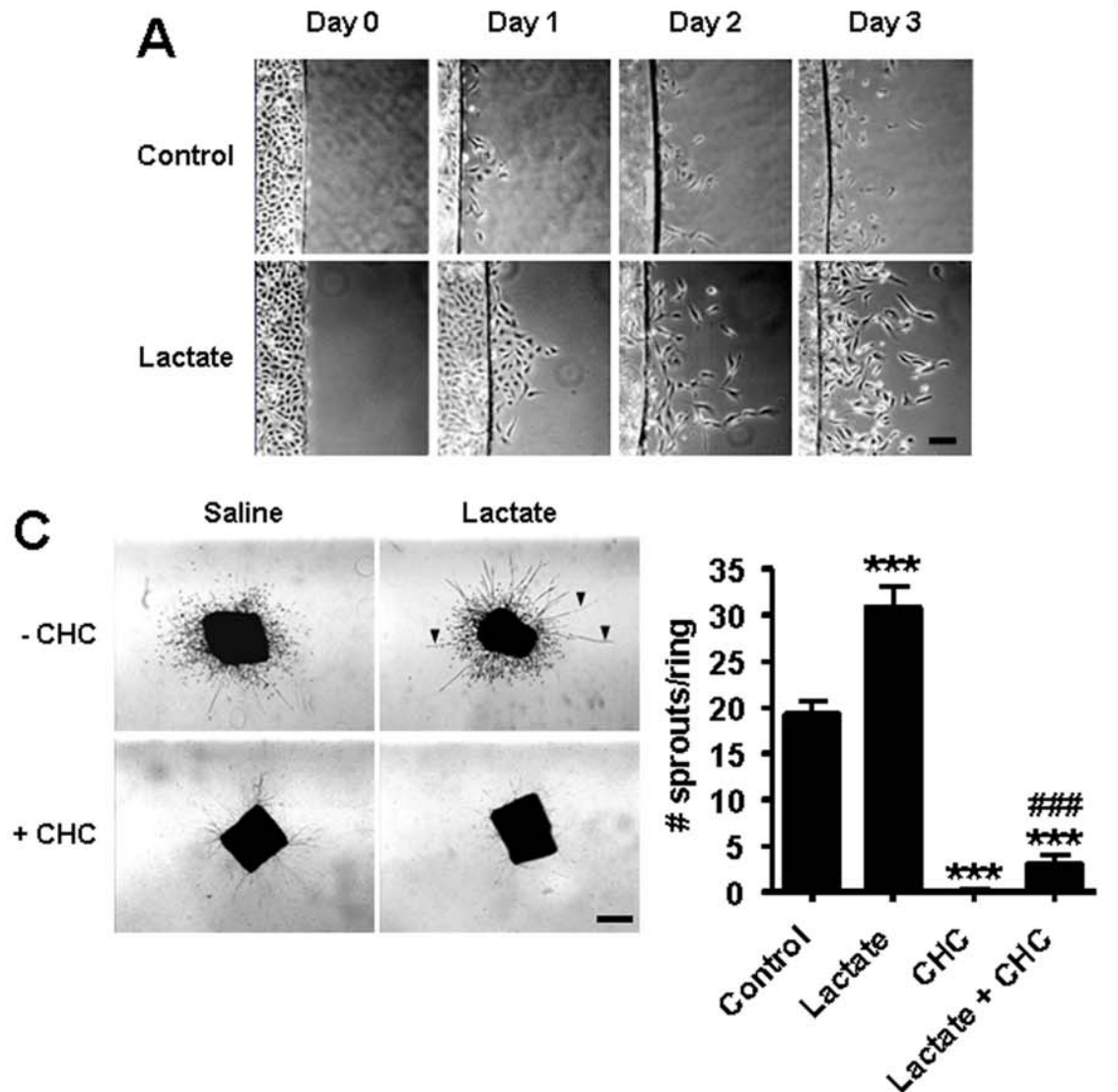

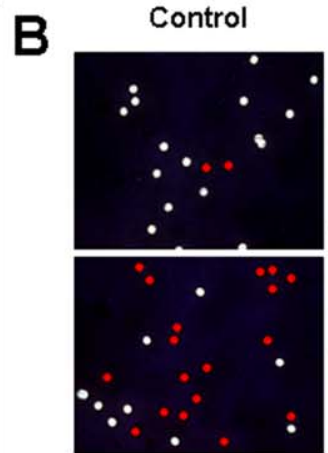

Lactate
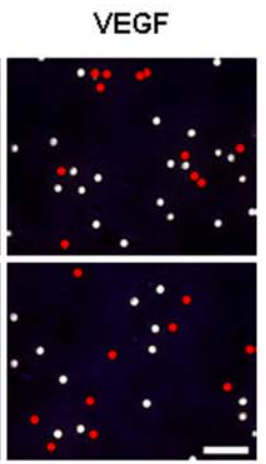

Lactate $+\mathrm{CHC}$

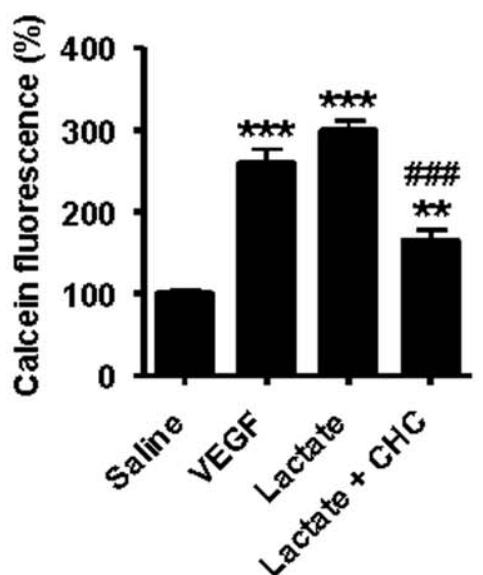

Figure 6. Targeting MCT1 inhibits lactate-induced endothelial cell migration and vascular sprouting. (A) Confluent BAECs on coverslips were placed into cell-free dishes in the presence of $10 \mathrm{mM}$ lactate or not. Pictures show cell migration over time. Bar $=50 \mu \mathrm{m}$. (B) Quantification of EC migration was performed in a transwell assay in which calcein-labeled BAECs migrated during 24-h through a Matrigel-coated membrane towards serum-free medium containing $10 \mathrm{ng} / \mathrm{ml} \mathrm{VEGF,} 10 \mathrm{mM}$ lactate, or lactate and $5 \mathrm{mM}$ CHC. Pictures show the membranes where pores occupied by endothelial cells (detected using a caveolin-1 antibody) are labeled with a red bullet. Bar $=50 \mu \mathrm{m}$. The graph shows calcein fluorescence in the bottom well. ${ }^{* *} p<0.01,{ }^{* * *} p<0.005$ compared to control; ${ }^{* \# \#} p<0.005$ compared to lactate; $n=3$. (C) Consecutive rings of a mouse aorta were cultured during 10 days in collagen gels containing $10 \mathrm{mM}$ lactate and/or $2 \mathrm{mM}$ CHC. Pictures show endothelial sproutings (arrowhead point at typical linear structures) and fibroblast seeding (scattered cells). Bar $=500 \mu \mathrm{m}$. The graph shows the number of sprouts per ring. ${ }^{* * *} p<0.005$ compared to control; \#\#\# $p<0.005$ compared to lactate; $n=6-11$. (B and C) Error bars reflect mean \pm SEM.

doi:10.1371/journal.pone.0033418.g006

as a pro-angiogenic agent. In a second set of experiments, we tested the anti-angiogenic activity of $\mathrm{CHC}$ in tumors. Comparison of size-matched mouse Lewis Lung carcinoma (LLc) tumors showed that chronic MCT1 inhibition reduced the endothelial density at vascular hotspots by $\sim 2$-fold compared to vehicle treatment (Figure 8B). In this model, CHC may interfere with the metabolic activity of MCT1-expressing tumor cells [26]. To better discriminate between direct and indirect anti-angiogenic effects, we repeated the experiment using MCT1-negative hepatocarcinoma (TLT) cells that were previously shown to be insensitive to the metabolic regulation by $\mathrm{CHC}$ [26]. Intravital microscopy revealed that chronic MCT1 inhibition completely prevented tumor angiogenesis in this model (Figure 8C). While new vascular structures continuously developed during the growth of salinetreated tumors, the angiogenic phenotype was lost in response to CHC administration (see pictures at day +12 ). Hemorrhagic foci were already observed after 8-days of treatment.

\section{Discussion}

The two main findings of our study are (i) that lactate stimulates HIF-1 activity directly in normoxic ECs resulting in the increased expression of relevant pro-angiogenic targets including the prototypical VEGF receptor VEGFR2, and (ii) that the antiangiogenic effects of MCT1 inhibition include inhibition of HIF-1 activation in ECs. This activity was initially identified in vitro using two different EC lines in which MCT1 was targeted pharmacologically or using RNA interference. It was confirmed in vivo by using the experimental MCT1 inhibitor CHC in two different tumor types.

Our demonstration is based on the unprecedented identification in ECs of a lactate-signaling pathway leading to HIF-1 activation under normoxia. This pathway involves lactate uptake, the conversion of lactate to pyruvate by LDH-B, a competition between pyruvate and 2-oxoglutarate supporting a pyruvatemediated inhibition of PHD2, and, consequently, HIF-1 activation independently of hypoxia (Figure 9). Lactate did not increase the oxygen consumption rate of ECs (see Figure S1B), ruling out a contribution of metabolic hypoxia to HIF-1 activation. A similar effect of monocarboxylates including pyruvate and lactate has been previously described in malignant cells by Lu et al. [21,22]. Final effectors are however different. While lactate was shown to promote VEGF production by tumor cells [22], we show here that in EGs, it upregulates VEGFR2 expression without modulating 

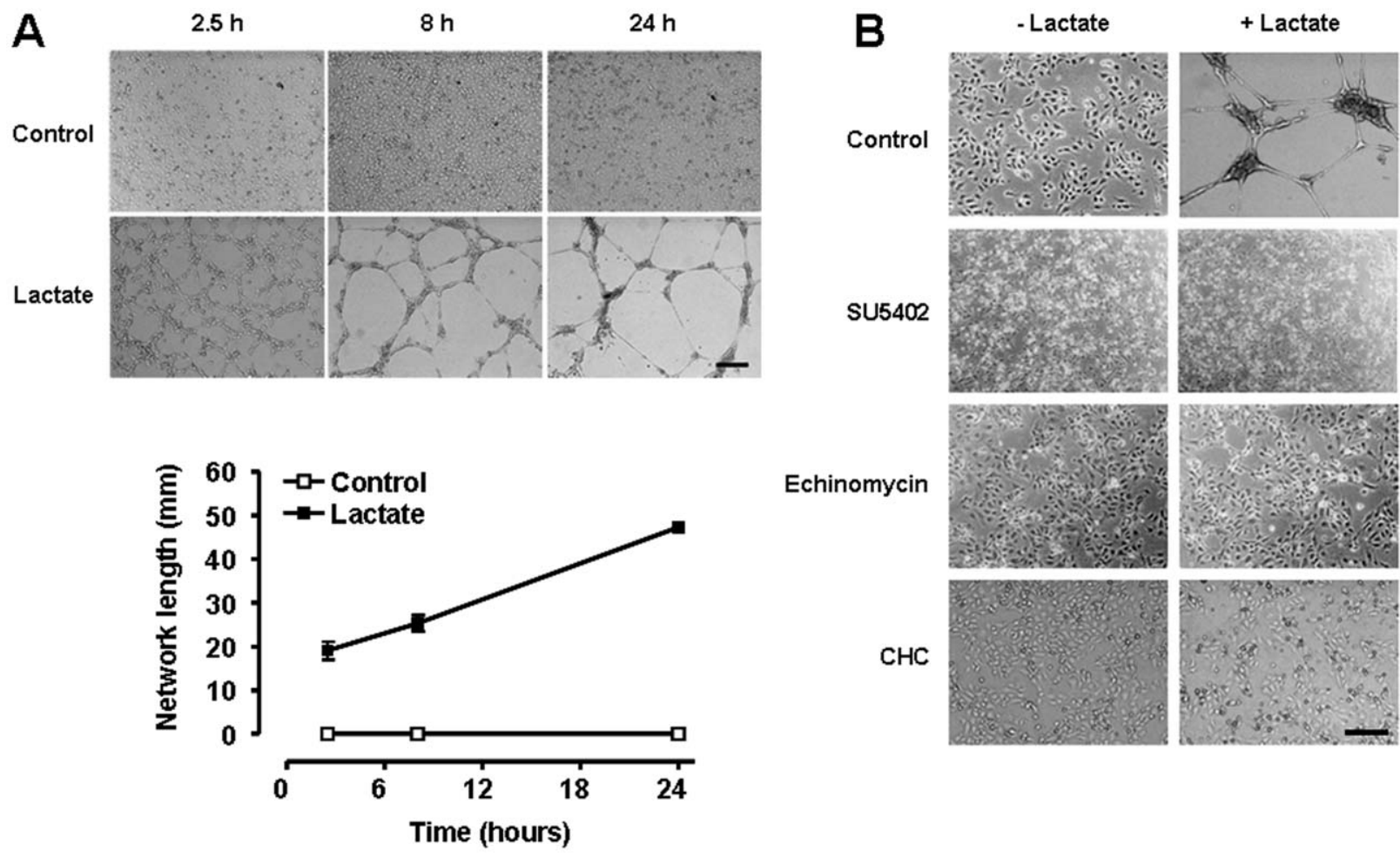

Echinomycin
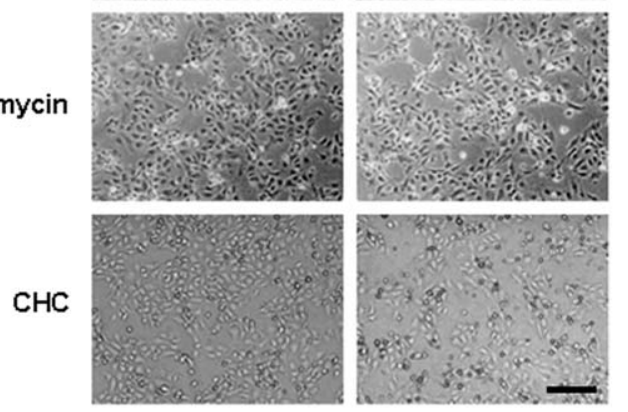

Figure 7. MCT1 inhibition blocks lactate-induced endothelial tube formation. HUVECs were seeded on growth factor-reduced Matrigel containing $10 \mathrm{mM}$ lactate or not and monitored for their ability to generate vascular tubes. (A) Pictures of the upper panel show endothelial network formation over time ( $\mathrm{bar}=500 \mu \mathrm{m})$, which was quantified in the lower graph. $n=4$. Error bars reflect mean \pm SEM and are sometimes smaller than symbols. (B) The tube formation assay was performed in the presence of $10 \mu \mathrm{M}$ SU5402 (targeting VEGF and bFGF receptors), $10 \mathrm{nM}$ echinomycin (targeting the transcriptional activity of HIF-1), or $2 \mathrm{mM}$ of CHC (targeting MCT1). Pictures were captured after 8-h of culture in the Matrigel matrix. Bar $=200 \mu \mathrm{m}$. doi:10.1371/journal.pone.0033418.g007

VEGF protein secretion despite increased $V E G F-A$ gene transcription. Because VEGFR2 is the main transducer of the proangiogenic effects of VEGF [27], one can logically propose that, in complex tumor tissues, lactate exquisitely stimulates VEGF signaling by acting on both the growth factor and its cognate receptor. This paradigm is further supported by the influence of lactate on stromal cells. Lactate indeed promotes VEGF production by fibroblasts and macrophages $[18,19]$, and enhances VEGF activity through inhibition of ADP-ribosylation in several cell types [18-20]. Of note, the existence of a HIF-1 $\alpha$-driven, VEGF-mediated autocrine loop in ECs could further reinforce the anti-angiogenic effects of MCT1 inhibition in ECs $[37,38]$. Finally, it should be emphasized that although the lactate induction of the VEGF/VEGFR2 signaling pathway is independent of hypoxia in the target cells, lactate may arise from anaerobic glycolysis [24] as well as aerobic glycolysis (the Warburg effect) [39], or through the malate shuttle from the oxidative metabolism of glucose and glutamine [40,41]. Lactate flux rate is likely to be different between "target" cells signaling through lactate vs cells consuming or producing lactate. For instance, while lactate-fueled respiration of tumor cells requires high-rate lactate uptake and high MCT1 expression [26], lower MCT1 expression in EGs could efficiently support the low-rate lactate uptake accounting for lactate signaling. Different levels of MCT1 expression could explain why Koukourakis et al. [42] failed to detect MCT1 in the vascular structures of colorectal adenocarcinomas using immunohistochemistry.

Although we focused on the paradigm that HIF-1 $\alpha$-driven VEGFR2 receptor expression is a target of MCT1 inhibition to account for the observed anti-angiogenic effects, inhibition of other pro-angiogenic HIF- $1 \alpha$ targets is very likely to support the functional impact of blocking lactate transport in ECs. For instance, we found that bFGF release was increased in response to lactate (Figure 2G) and thus that in the absence of increased VEGF, the inhibition of lactate-induced tubulogenesis on Matrigel with SU4502, a mixed inhibitor of VEGFR2 and fibroblast growth factor receptor 1 (FGFR1) (Figure 7B), strongly suggests that bFGF participates to the pro-angiogenic effects of lactate. Of interest is also the ability of bFGF to stimulate the activity of aminophospholipid translocase in ECs [43], an enzyme required for the maintenance of lipid asymmetry of the membrane, proper membrane anchorage of proteins, endocytosis and membrane recycling $[44,45]$. In erythrocytes, GLUT-dependent arabinose transport and MCT-dependent lactate transport were shown to be inhibited by cleavage of either phosphatidylcholine or sphingomyelin [46], stressing out that membrane fluidity and asymmetry are important for the activity of these transporters. Whether lactate-induced bFGF production facilitates the membrane translocation of transporters (such as MCT1) and receptors (such as bFGFR and VEGFR2) involved in the angiogenic phenotype of ECs warrants further investigation.

More generally, previous work indicates that targeting MCT1 offers the possibility to simultaneously inhibit several major proangiogenic pathways with a single therapeutic molecule. First, MCT1 inhibition may interfere with the viability of angiogenicfactor-producing-cells including cancer cells, macrophages and fibroblasts; all these cells express MCT1 [26,42]. Note that the impact may be indirect since MCT1 inhibition in oxidative tumor cells may favor the death of hypoxic glycolytic cells [26], and alteration in the fibroblast capacity to take up lactate and export pyruvate (both through MCT1) in tumors may reduce tumor cell 
A

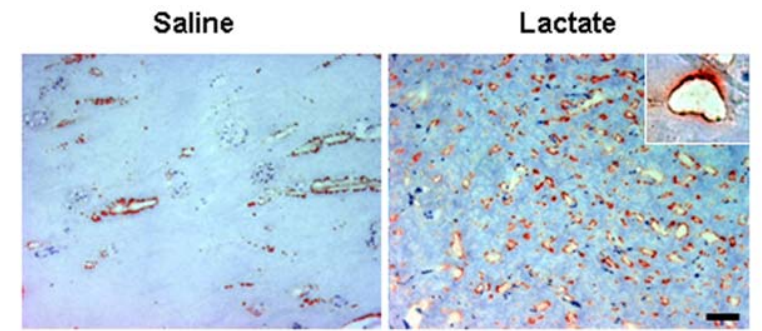

B

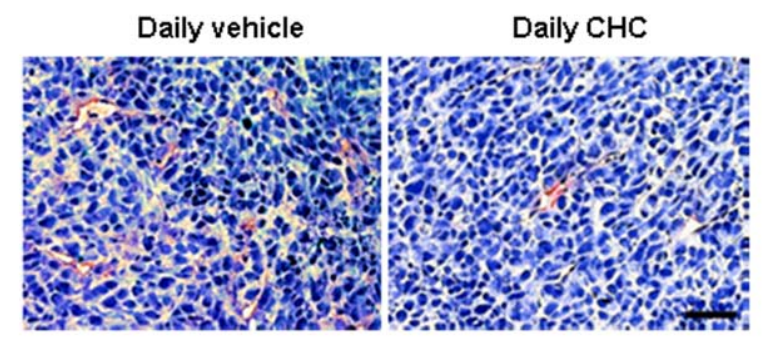

C

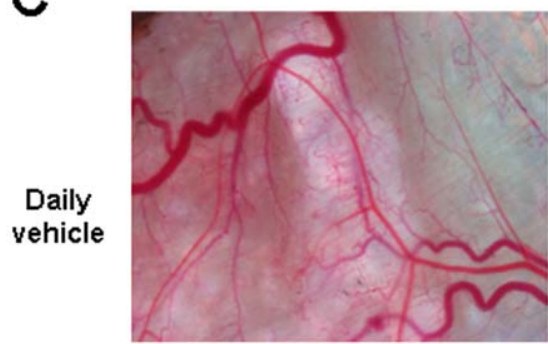

Day +4

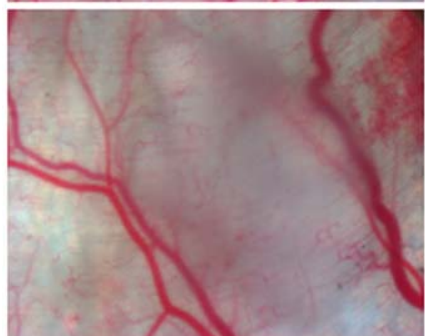

Day +8
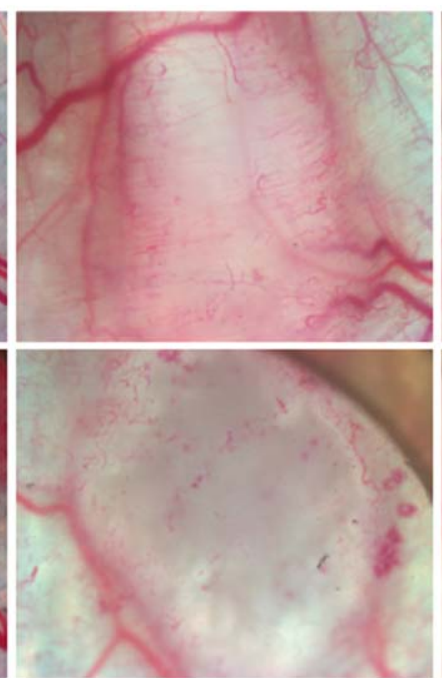
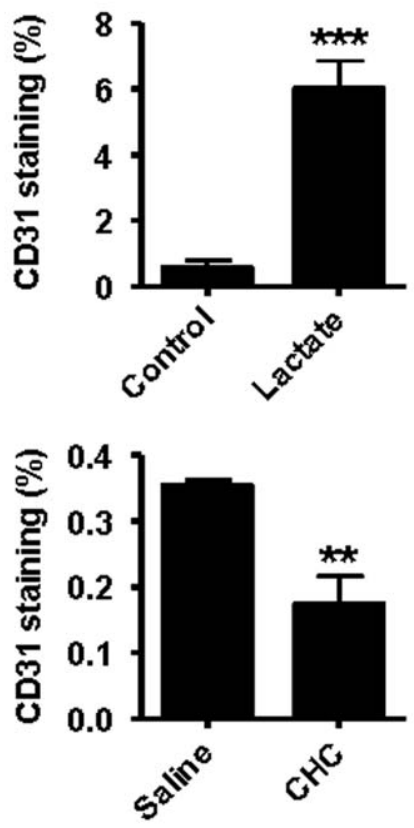

Day +12

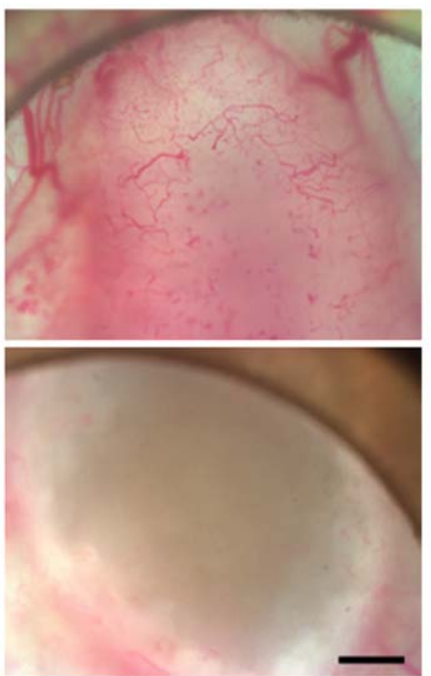

Figure 8. MCT1 inhibition blocks tumor angiogenesis. (A) Two Matrigel plugs were implanted subcutaneously in the same mouse, one containing $10 \mathrm{mM}$ lactate (left flank) and the other one an equal volume of saline (right flank). Plugs were microdissected 7 days after implantation. Pictures show CD31 immunostainings ( $\mathrm{bar}=100 \mu \mathrm{m}$; inset: a vascular structure carrying red blood cells), which were quantified in the graph. ${ }^{* * *} p=0.0007 ; n=4$. Error bars reflect mean \pm SEM. (B and C) On Day 0 , mice were randomly assigned to treatment groups consisting of daily i.p. injections of CHC $(1 \mathrm{mmol} / \mathrm{Kg})$ or vehicle. (B) Mice carrying LLc tumors $(4 \pm 1 \mathrm{~mm})$ were treated. Pictures show CD31 immunostainings of sizematched tumors $(\mathrm{bar}=20 \mu \mathrm{m})$, which were quantified in the graph. ${ }^{* *} p=0.0051 ; n=4$. Error bars reflect mean \pm SEM. (C) Intravital microscopy pictures were captured over time in treated mice carrying tumors generated with MCT1-negative TLT tumor cells. Bar $=1 \mathrm{~mm}$.

doi:10.1371/journal.pone.0033418.g008

proliferation [42]. Second, as documented in a previous study, MCT1 inhibition can block lactate-induced NF- $\mathrm{KB}$ activation in ECs, with a subsequent downregulation of autocrine IL-8 signaling and IL-8-mediated angiogenesis [23]. Interestingly, this latter effect was also in part dependent on a direct competition between 2-oxoglutarate and lactate for PHD2. Given this mode of action, other targets may be anticipated. For example, 2-oxoglutarate is a necessary cofactor for factor inhibiting HIF-1 (FIH-1), a 2oxoglutarate-dependent dioxygenase that inactivates HIF-1 through HIF-1 $\alpha$ asparagine hydroxylation [47]. Because PHDs and FIH-1 are simultaneously inhibited by compounds such as dimethyloxalylglycine that displace 2-oxoglutarate from the active enzyme sites [48], our data suggest that lactate-dependent dioxygenase inhibition may extend to FIH-1. Both PHD2 and FIH-1 also control HIF-2 activity through regulating HIF-2 $\alpha$ hydroxylations [49], suggesting that the activity of lactate could further include HIF-2 activation in ECs. HIF-1 and HIF-2 control both different and overlapping sets of genes modulating angiogenesis and vascular stability and maturation, respectively [5053]. Whether the detection of mature blood vessels in lactate- 


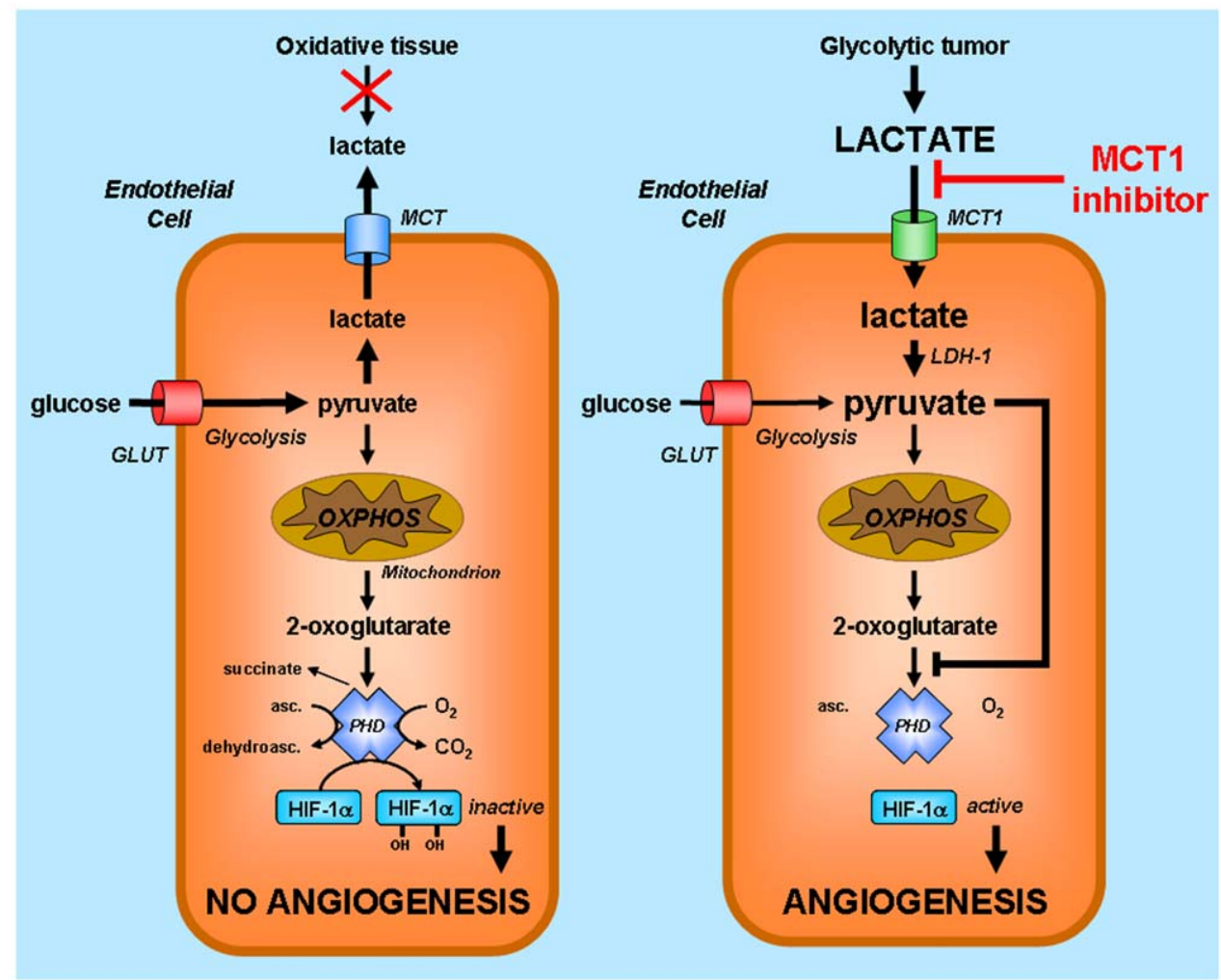

Figure 9. Model illustrating the anti-angiogenic activity of MCT1 inhibitors targeting lactate-induced HIF-1 activation in endothelial cells. HIF-1 activity primarily depends on the stability of HIF-1 $\alpha$. When HIF prolylhydroxylase (PHD) is active as it is the case for normoxic endothelial cells (ECs) in oxidative tissues (left), HIF-1 $\alpha$ is hydroxylated and addressed to the proteasome for degradation. PHD requires 2-oxoglutarate as a substrate and is competitively inhibited by pyruvate. Normoxic ECs in glycolytic tissues such as tumors (right) take up exogenous lactate originating from distant hypoxic cells, a process under the control of monocarboxylate transporter 1 (MCT1). ECs do not primarily use lactate as a fuel for oxidative phosphorylation (OXPHOS). Lactate oxidation by LDH-B rather increases the pool of intracellular pyruvate, now available to compete with 2-oxoglutarate from PHD, resulting in HIF-1 $\alpha$ protein stabilization, HIF-1 activation, and angiogenesis. Because MCT1 is the main transporter for lactate uptake by ECs, targeting MCT1 inhibits lactate-induced angiogenesis in tumors. Abbreviations: asc., ascorbate; dehydroasc., dehydroascorbate; GLUT, glucose transporter.

doi:10.1371/journal.pone.0033418.g009

containing Matrigel plugs (Figure 8A) and the apparent antivascular effects of MCT1 inhibition in vivo (Figure 8C) are related to changes in endothelial HIF-2 activity remains to be determined. The anti-angiogenic effects of MCT1 inhibitors that we document here offers an additional rationale for the antitumor effects of MCT1 inhibitors that we identified previously in several types of tumors and attributed to metabolic effects [26]. In a model of colon cancer xenograft involving the co-injection of HUVECs, a downregulation of MCT1 expression in ECs was indeed documented to significantly retard tumor growth [23].

In conclusion, we have shown that lactate activates HIF-1 in normoxic ECs and consecutively promotes the expression of bFGF and VEGFR2, the latter reinforcing the stimulation of the VEGF signaling pathway promoted by the lactate-induced VEGF expression occurring in tumor and stromal cells. Importantly, we also report that in ECs, MCT1 inhibition can thus drive direct anti-angiogenic effects through a reduction in HIF-1 activity, which, together with the antimetabolic effects of MCT1 inhibition on tumor cells, considerably enlarges the therapeutic potential of this class of drugs.

\section{Materials and Methods}

\section{Cells and chemicals}

BAECs (Clonetics) were routinely cultured in EBM-EGM (Cambrex), HUVECs (Clonetics) in EBM2-MV (Cambrex), and
LLc (LGC Standards, [54]) and TLT (originally obtained at from HS Taper, University of Louvain [55]) tumor cells in DMEM containing $4500 \mathrm{mg} /$ liter glucose (Invitrogen) with $10 \% \mathrm{FBS}$ at $5 \% \mathrm{CO}_{2}$ and $21 \% \mathrm{O}_{2}, 37^{\circ} \mathrm{C}$. Glucose-deprived DMEM was from Krackeler Scientific. Media were supplemented with $1 \%$ penicillin-streptomycin. All experiments were performed in pyruvate-free media buffered at $\mathrm{pH} 7.3$ (3.7 g/liter $\left.\mathrm{NaHCO}_{3}\right)$. To minimize fluctuations due to unequal growth rates, all assays were performed on confluent cells. Hypoxia $\left(1 \% \mathrm{O}_{2}\right)$ was achieved as previously described [56]. Cell death was quantified using the NucleoCounter device from ChemoMetec. Unless stated otherwise, all chemicals including CHC were from Sigma. Carboxylates were used as sodium salts.

\section{Determination of intracellular L-lactate and pyruvate}

For NMR experiments, HUVECs in EBM2 media were incubated during 6-h to $10 \mathrm{mM}{ }^{13} \mathrm{C}$-methyl-labeled lactate (Isotec, Sigma), washed twice with DPBS, lysed and collected in $0.9 \mathrm{M}$ perchloric acid $\left(1: 10\right.$ in $\left.\mathrm{diH}_{2} \mathrm{O}\right) .{ }^{12} \mathrm{C}$-(unlabeled)-lactate was used as control. Lysates were spun at $4{ }^{\circ} \mathrm{C}$ for $10 \mathrm{~min}$ at $12,000 \mathrm{rpm} .{ }^{13} \mathrm{C}$ and ${ }^{1} \mathrm{H}$ NMR spectra acquisitions were performed on supernatants using a 500-MHz Varian Inova spectrometer equipped with a 5$\mathrm{mm}$ tunable broadband probe. ${ }^{13} \mathrm{C}-\mathrm{NMR}$ spectra were acquired at 125.7 MHz with $45^{\circ}$ flip angle, 0.8-second interpulse delay, a $1.334 \mathrm{~s}$ acquisition time, and at a temperature of $25^{\circ} \mathrm{C}$. Control runs of known concentrations of lactate were used to assess peak 
shape and ppm position. VNMRJ software by Varian (Cary, NC) was used to acquire and analyze spectra. All samples were tuned and shimmed before data acquisition. For enzymatic measurements, confluent HUVECs were incubated with $10 \mathrm{mM} L$-lactate, washed twice with PBS containing $10 \mathrm{mM} D$-Lactate (to saturate MCTs), and lysed in $200 \mu \mathrm{l}$ ice-cold RIPA Buffer $(50 \mathrm{mM}$ Tris HCL pH 7.4, $150 \mathrm{mM} \mathrm{NaCl,} 1 \%$ Triton-x 100, 0.05\% sodium deoxycolate, $0.1 \%$ SDS, $1 \mathrm{mM}$ EDTA, $1 \mathrm{mM} \mathrm{Na} \mathrm{NO}_{4}$ and protease inhibitors). Samples were filtered through centrifugation columns with a $10 \mathrm{KDa}$ cutoff. $L$-Lactate and pyruvate concentrations were quantified in clear cell lysates using specific enzymatic assays on an ISCUS $^{\text {flex }}$ analyzer (CMA Microdialysis AB).

\section{Oximetry}

Determination of cell oxygen consumption rates was carried out using electron paramagnetic resonance (EPR) in DMEM containing $4500 \mathrm{mg} /$ liter glucose, dextran 10\% [57]. Briefly, $2 \times 10^{7}$ viable cells $/ \mathrm{ml}$ were sealed in glass capillary tubes in the presence of $0.08 \mathrm{mM}$ of the $\mathrm{O}_{2}$ sensor 4-oxo-2,2,6,6-tetramethylpiperidined-15N-1-oxyl (CDN isotopes) and with $10 \mathrm{mM}$ lactate where indicated. Cells were maintained at $37^{\circ} \mathrm{C}$ during recording on a Bruker EMX EPR spectrometer operating at $9 \mathrm{GHz}$.

\section{Dual luciferase reporter assays}

Dual luciferase reporter assays were performed with the dual luciferase kit (DLR) from Promega using pGL3-(PGK-HRE6)TK-Luc as reporter of HIF-1 activity [10] and pODD-Luc as reporter of PHD activity [30]. Cells were transfected using electroporation (Amaxa Nucleofector, Lonza).

\section{Western blotting, immunohistochemistry and antibodies}

We used previously disclosed protocols for immunocytochemistry and immunohistochemistry [58] except that HUVECs were permeabilized with $0.05 \%$ saponin for MCT1 detection. Western blotting (WB) was done as previously shown [59] with the slight modification that proteins were not heat-denaturated for HIF-1 $\alpha$ protein detection. This allowed the detection, in whole cell lysates, of basal HIF- $1 \alpha$ that would otherwise not be detected [60]. For Figure S2, nuclear extraction was performed according to manufacturer's recommendations using the nuclear extraction kit from Active Motif. Primary antibodies were: a mouse monoclonal against HIF- $1 \alpha(\mathrm{BD})$, a rabbit polyclonal raised against an intracellular epitope of MCT1 (AB3538P, Chemicon), a rabbit polyclonal against caveolin-1 (BD), a rabbit polyclonal against laminin A/C (Santa Cruz), a goat polyclonal raised against an epitope comprising an an extracellular domain of VEGFR2 (R\&D) for immunohistochemistry, a mouse monoclonal against VEGFR2 (Santa Cruz) for WB, a mouse monoclonal against CD147 (BD), a mouse monoclonal against $\beta$ actin (Sigma), a mouse monoclonal against CD31 (Dako) for Figure $\mathrm{S} 3$, and a rat monoclonal against GD31 (BD) for Figure 8. For immunohistochemistry, areas of positive staining were quantified using the Framework for Image Dataset Analysis (FRIDA) software developed by Johns Hopkins University.

\section{ELISA}

VEGF-A and bFGF protein levels were measured in the supernatant of confluent HUVECs using the Human VEGF Quantikine ELISA Kit (R\&D) and the Human bFGF Quantikine ELISA kit (R\&D) according to manufacturer's instructions.

\section{PCR and RNA interference}

The effects of a 24-h exposure of HUVECs to lactate and saline were compared using the Human Angiogenesis RT2 Profiler PGR
Array from SABiosciences, according to manufacturer's instructions. In each condition, total mRNA extracted from 3 independent dishes was pooled. To silence MCT1 and $L D H-B$ mRNAs, HUVECs were transfected with specific siRNAs as reported previously [61]. siRNAs (Qiagen) targeted the following sequences: hMCT1 AAGAGGGUGACUUUUCGAAAU, hLDHB AAGAUUGUAGUGGUAACUGCA. Allstar siRNA (Qiagen) was used as negative control. MCT1 shRNA was purchased from Open Biosystems (clone TRCN0000038340); scrambled control shRNA was Addgene plasmid 1864. The following primers were used for SYBR green quantitative PCR [61]: hMCT1 sense, 5'-GTGGCTCAGGTCGGTATTGT-3', antisense, 5'-GAGCGGACGTAAAAGTGGTG-3'; hMCT2 sense, 5'-CAACACCATTCGAAGACAGC-3', antisense 5'-TGGGTGTTATGTACGGAGGA-3'; hMCT3 sense, 5' - GGATGTGTT-GAAGAACTATGAGATC3', antisense 5'-CGGGGTTCGTCTGCAACA-3'; hMCT4 sense, 5'-CAGTTCGAGGTGCTCATGG-3', antisense, 5'- ATGTAGACGTGGGTCGCAT-3'. Housekeeping human ribosomal protein L19 (hRPL19) primers were sense, 5'-CAAGGGGATTCTCATGGAACA-3', antisense, 5'-TGGTCAGCGAGGAGCTTCTT-3'.

\section{Endothelial cell migration assays}

To image EC migration, we used an assay analogous to a scratch injury test [62]. BAECs were cultured to confluence on gelatincoated circular coverslips, which were then transferred to adhere onto $100 \mathrm{~mm}$ gelatin-coated dishes containing EBM-EGM without serum and growth factors, and supplemented with lactate $(10 \mathrm{mM})$ or not. Images of migrating cells were captured at the migration front around the coverslip margin. For quantification, BAECs were prestained with calcein and 50,000 cells were seeded in the upper chamber of the Matrigel-coated insert plate of a Biocoat Tumor Invasion System (BD). Bottom wells contained EGM-MV without serum and growth factors, supplemented with lactate $(10 \mathrm{mM})$, VEGF $(10 \mathrm{ng} / \mathrm{ml}$, Sanvertech), CHC (5 mM) and/or saline. Twenty-four hours later, cells on the underside of the Fluoroblock membranes were quantified by measuring fluorescence at $535 \mathrm{~nm}$ after an excitation at $485 \mathrm{~nm}$. Detached membranes were also fixed in $4 \%$ paraformaldehyde for 10 minutes and processed for immunohistochemistry using anti-caveolin-1 antibodies.

\section{Endothelial tube formation and aortic ring angiogenesis assays}

Capillary-like tube formation [63] and mouse aorta ring assays [35] were performed as previously described. Where indicated, inhibitors were present both in the gels and in the supernatants.

\section{In vivo experiments}

All mice were from Elevage Janvier. Where indicated, vehicle or CHC $(25 \mu \mathrm{mol}$ in $200 \mu \mathrm{l}$, [64]) was daily injected i.p. We used RJ:NMRI mice and an existing protocol for Matrigel plug implantation [58]. The protocols used for intramuscular tumor growth and intravital microscopy have also been reported previously $[65,66]$. LLc cells were injected into syngeneic male 6-8 week-old C57/Bl6 J mice and TLT cells into syngeneic male RJ:NMRI mice. Surgery and imaging were performed on anesthetized (ketamine/xylazine) animals. All in vivo experiments were performed with approval of Duke University Institutional Animal Care and Use Committee (specific approval ID for this study was A069-03-02) and by Université catholique de Louvain (UCL) authorities (Comité d'Ethique Facultaire pour l'Experimentation Animale, specific approval ID for this study was TUMETABO) according to national animal care regulations. 


\section{Statistical analyses}

Results are expressed as mean \pm SEM. Student's $t$ test and 1way ANOVA (Tukey's post-hoc test) were used where convenient. $p<0.05$ was considered statistically significant.

\section{Supporting Information}

Figure S1 Lactate does not support EG survival through increased oxygen consumption and $\mathrm{CHC}$ is devoid of intrinsic toxicity. (A) HUVEG death was determined with a NucleoCounter. Confluent cells were assayed after 4-h of culture in serum-free DMEM containing the indicated substrates. $*_{p}<0.05$ compared to glucose; $n=3$. (B) EPR oximetry was used to determine the rate of oxygen consumption by HUVECs in DMEM containing $4500 \mathrm{mg} / \mathrm{L}$ glucose $\pm 10 \mathrm{mM}$ lactate. Slopes calculated from linear regressions are not statistically different $(-1.973 \pm 0.174$ for glucose, $-1.902 \pm 0.275$ for glucose+lactate, $p=0.84, n=3$ ). (A and B) Error bars reflect mean \pm SEM. (PDF)

Figure S2 Lactate induces the nuclear translocation of HIF-1 $\alpha$ in HUVEGs. HIF- $1 \alpha$ protein expression was detected by Western blot in the cytosol (laminin A/C-negative fraction, $8 \mu \mathrm{g}$ of total protein per well) and nucleus (laminin A/C-positive fraction, $10 \mu \mathrm{g}$ of total protein per well) of HUVECs after a 24-h treatment with hypoxia or lactate as indicated. Densitometric analyses of HIF- $1 \alpha$ protein expression (\% of control) are provided below the corresponding bands; the experiment was repeated twice with similar results. (PDF)

Figure S3 Membrane expression of VEGFR2 and MCT1 in ECs. (A) HUVECs were treated during $24 \mathrm{~h}$ with $10 \mathrm{mM}$ lactate or not, after which the cells were immunostained with an antibody raised against an epitope comprising an extracellular domain of VEGFR2. Nuclei were stained with DAPI. Shown are representative pictures indicating that lactate stimulates the membrane expression of VEGFR2 in normoxic ECs. Omission of primary antibodies was used for control. (bar $=20 \mu \mathrm{m}$ ). (B) HUVECs were immunostained using antibodies against MCT1, its chaperon protein CD147, and CD31, and nuclei were stained with DAPI. Shown are representative pictures, including a merged picture, indicating that all 3 proteins colocalize at the cell membrane. Omission of primary antibodies was used for control. (bar $=20 \mu \mathrm{m}$ ).

(PDF)

Figure S4 Inhibition of lactate-induced HIF-1 $\alpha$ expression by 2-oxoglutarate, oxamate and LDH-B silencing. Representative western blots are shown. (A and B) HIF- $1 \alpha$ and $\beta$ actin protein expressions were detected in BAECs treated during 24-h as indicated with (A) $10 \mathrm{mM}$ lactate and increasing concentrations of the PDH substrate 2-oxoglutarate (2-OG), (B) $10 \mathrm{mM}$ lactate and/or $10 \mathrm{mM}$ oxamate. (C) HUVEGs were transfected with a specific siRNA against $L D H-B$ or with a

\section{References}

1. Hanahan D, Weinberg RA (2011) Hallmarks of cancer: the next generation. Cell 144: 646-674.

2. Wu R, Racker E (1959) Regulatory mechanisms in carbohydrate metabolism. IV. Pasteur effect and Crabtree effect in ascites tumor cells. J Biol Chem 234: 1036-1041.

3. Semenza GL (1998) Hypoxia-inducible factor 1: master regulator of O2 homeostasis. Curr Opin Genet Dev 8: 588-594.

4. Elstrom RL, Bauer DE, Buzzai M, Karnauskas R, Harris MH, et al. (2004) Akt stimulates aerobic glycolysis in cancer cells. Cancer Res 64: 3892-3899.

5. Gordan JD, Thompson CB, Simon MC (2007) HIF and c-Myc: sibling rivals for control of cancer cell metabolism and proliferation. Cancer Cell 12: 108-113.

6. Carmeliet P, Jain RK (2000) Angiogenesis in cancer and other diseases. Nature 407: 249-257. scrambled siRNA, and treated during 24-h with $20 \mathrm{mM}$ lactate where indicated. The representative western blot shows HIF-1 $\alpha$, $\mathrm{LDH}-\mathrm{B}$ and $\beta$-actin protein expressions.

(PDF)

Figure S5 Protein extinctions in HUVEGs after siRNA/ ShRNA delivery. Representative western blots and quantification graphs are shown for HUVECs transfected with (A) a specific siRNA against $L D H-B$ or a control siRNA $(n=2)$, or $(\mathrm{B})$ a specific shRNA against MCT1 or a control shRNA. $n=3$. (A and B) Error bars reflect mean \pm SEM.

(PDF)

Figure S6 GHC is devoid of intrinsic toxicity for ECs. HUVEC death was determined with a NucleoCounter. Confluent cells were assayed after 24-h culture in EBM2-MV containing glucose and serum and supplemented with lactate or CHC as indicated. $n s$, non-significant; $n=4$. Error bars reflect mean \pm SEM. (PDF)

Figure S7 Various MCT1 inhibitors block lactate-induced HIF-1 $\alpha$ protein expression in normoxic ECs. BAECs were treated during 24-h with $10 \mathrm{mM}$ lactate and the MCT1 inhibitors indicated. $*_{p}<0.05, * * p<0.01$ compared to control; ${ }^{\# \#} p<0.01$, \#\#\# $p<0.005$ compared to lactate alone; $n=4$. Error bars reflect mean \pm SEM. NPPB, 5-nitro-2-[3-phenylpropylamino]-benzoate. (PDF)

Figure S8 MCT1 modulates basal and lactate-induced angiogenesis. HUVEGs transfected with a shRNA against MCT1 (target extinction $=86.7 \pm 3.3 \%$ ) or with a scrambled $(\mathrm{Scr})$ shRNA were seeded on undiluted growth factor-reduced Matrigel containing $10 \mathrm{mM}$ lactate or not and monitored for their ability to generate vascular tubes. Shown are representative pictures $(n=3)$ captured after 12-h of culture. Bar $=1 \mathrm{~mm}$.

(PDF)

Table S1 Genes activated by lactate in normoxic EGs (RT2 Profiler PGR Array).

(PDF)

\section{Acknowledgments}

The authors thank Prof. Chuan-Yuan Li (University of Colorado, Denver) for the kind gift of the ODD-Luc construct, Dr Paolo Porporato (UCL, Brussels) for scientific and technical advices, and Elise Beneteau for excellent technical assistance.

\section{Author Contributions}

Conceived and designed the experiments: PS BG CM MWD OF. Performed the experiments: PS TC CJDS FV JV KMK EJM SD PD FF AR. Analyzed the data: PS TC GJDS FV JV KMK EJM SD PD FF BG AR CM MWD OF. Contributed reagents/materials/analysis tools: PS BG AR GM MWD OF. Wrote the paper: PS MWD OF.

7. Pugh CW, Ratcliffe PJ (2003) Regulation of angiogenesis by hypoxia: role of the HIF system. Nat Med 9: 677-684.

8. Berra E, Benizri E, Ginouves A, Volmat V, Roux D, et al. (2003) HIF prolylhydroxylase 2 is the key oxygen sensor setting low steady-state levels of HIFlalpha in normoxia. EMBO J 22: 4082-4090.

9. Hirsila M, Koivunen P, Gunzler V, Kivirikko KI, Myllyharju J (2003) Characterization of the human prolyl 4-hydroxylases that modify the hypoxiainducible factor. J Biol Chem 278: 30772-30780.

10. Maxwell PH, Wiesener MS, Chang GW, Clifford SC, Vaux EG, et al. (1999) The tumour suppressor protein VHL targets hypoxia-inducible factors for oxygen-dependent proteolysis. Nature 399: 271-275.

11. Semenza GL (2003) Targeting HIF-1 for cancer therapy. Nat Rev Cancer 3: $721-732$. 
12. Semenza GL (2010) HIF-1: upstream and downstream of cancer metabolism. Curr Opin Genet Dev 20: 51-56.

13. Unruh A, Ressel A, Mohamed HG, Johnson RS, Nadrowitz R, et al. (2003) The hypoxia-inducible factor-1 alpha is a negative factor for tumor therapy. Oncogene 22: 3213-3220.

14. Brahimi-Horn MC, Chiche J, Pouyssegur J (2007) Hypoxia and cancer. J Mol Med 85: 1301-1307.

15. Fraisl P, Mazzone M, Schmidt T, Carmeliet P (2009) Regulation of angiogenesis by oxygen and metabolism. Dev Cell 16: 167-179.

16. Green H, Goldberg B (1964) Collagen and cell protein synthesis by an established mammalian fibroblast cell line. Nature 204: 347-349.

17. Hunt TK, Aslam RS, Beckert S, Wagner S, Ghani QP, et al. (2007) Aerobically derived lactate stimulates revascularization and tissue repair via redox mechanisms. Antioxid Redox Signal 9: 1115-1124.

18. Trabold O, Wagner S, Wicke C, Scheuenstuhl H, Hussain MZ, et al. (2003) Lactate and oxygen constitute a fundamental regulatory mechanism in wound healing. Wound Repair Regen 11: 504-509.

19. Constant JS, Feng.JJ, Zabel DD, Yuan H, Suh DY, et al. (2000) Lactate elicits vascular endothelial growth factor from macrophages: a possible alternative to hypoxia. Wound Repair Regen 8: 353-360.

20. Xiong M, Elson G, Legarda D, Leibovich SJ (1998) Production of vascular endothelial growth factor by murine macrophages: regulation by hypoxia, lactate, and the inducible nitric oxide synthase pathway. Am J Pathol 153: 587-598.

21. Lu H, Forbes RA, Verma A (2002) Hypoxia-inducible factor 1 activation by aerobic glycolysis implicates the Warburg effect in carcinogenesis. J Biol Chem 277: 23111-23115

22. Lu H, Dalgard CL, Mohyeldin A, McFate T, Tait AS, et al. (2005) Reversible inactivation of HIF-1 prolyl hydroxylases allows cell metabolism to control basal HIF-1. J Biol Chem 280: 41928-41939.

23. Vegran F, Boidot R, Michiels C, Sonveaux P, Feron O (2011) Lactate influx through the endothelial cell monocarboxylate transporter MCT1 supports an NF-kappaB/IL-8 pathway that drives tumor angiogenesis. Cancer Res 71: 2550-2560.

24. Walenta S, Schroeder T, Mueller-Klieser W (2004) Lactate in solid malignant tumors: potential basis of a metabolic classification in clinical oncology. Curr Med Chem 11: 2195-2204.

25. Walenta S, Snyder S, Haroon ZA, Braun RD, Amin K, et al. (2001) Tissue gradients of energy metabolites mirror oxygen tension gradients in a rat mammary carcinoma model. Int J Radiat Oncol Biol Phys 51: 840-848.

26. Sonveaux P, Vegran F, Schroeder T, Wergin MC, Verrax J, et al. (2008) Targeting lactate-fueled respiration selectively kills hypoxic tumor cells in mice. J Clin Invest 118: 3930-3942.

27. Kerbel RS (2008) Tumor angiogenesis. N Engl J Med 358: 2039-2049.

28. Forsythe JA, Jiang BH, Iyer NV, Agani F, Leung SW, et al. (1996) Activation of vascular endothelial growth factor gene transcription by hypoxia-inducible factor 1. Mol Cell Biol 16: 4604-4613.

29. Calvani M, Rapisarda A, Uranchimeg B, Shoemaker RH, Melillo G (2006) Hypoxic induction of an HIF-lalpha-dependent bFGF autocrine loop drives angiogenesis in human endothelial cells. Blood 107: 2705-2712.

30. Li F, Sonveaux P, Rabbani ZN, Liu S, Yan B, et al. (2007) Regulation of HIFlalpha stability through S-nitrosylation. Mol Cell 26: 63-74.

31. Wilkinson JH, Walter SJ (1972) Oxamate as a differential inhibitor of lactate dehydrogenase isoenzymes. Enzyme 13: 170-176.

32. Halestrap AP, Price NT (1999) The proton-linked monocarboxylate transporter (MCT) family: structure, function and regulation. Biochem J 343 Pt 2: 281-299.

33. Halestrap AP, Meredith D (2004) The SLC16 gene family-from monocarboxylate transporters (MCTs) to aromatic amino acid transporters and beyond. Pflugers Arch 447: 619-628.

34. Manning Fox JE, Meredith D, Halestrap AP (2000) Characterisation of human monocarboxylate transporter 4 substantiates its role in lactic acid efflux from skeletal muscle. J Physiol 529 Pt 2: 285-293.

35. Masson V, Devy L, Grignet-Debrus C, Bernt S, Bajou K, et al. (2002) Mouse aortic ring assay: A new approach of the molecular genetics of angiogenesis. Biol Proced Online 4: 24-31.

36. Sonveaux P, Martinive P, DeWever J, Batova Z, Daneau G, et al. (2004) Caveolin-1 expression is critical for vascular endothelial growth factor-induced ischemic hindlimb collateralization and nitric oxide-mediated angiogenesis. Circ Res 95: 154-161.

37. Tang N, Wang L, Esko J, Giordano FJ, Huang Y, et al. (2004) Loss of HIFlalpha in endothelial cells disrupts a hypoxia-driven VEGF autocrine loop necessary for tumorigenesis. Cancer Cell 6: 485-495.

38. Deudero JJ, Caramelo C, Castellanos MC, Neria F, Fernandez-Sanchez R, et al. (2008) Induction of hypoxia-inducible factor lalpha gene expression by vascular endothelial growth factor. J Biol Chem 283: 11435-11444.

39. Vander Heiden MG, Cantley LC, Thompson CB (2009) Understanding the Warburg effect: the metabolic requirements of cell proliferation. Science 324: 1029-1033.

40. Feron O (2009) Pyruvate into lactate and back: from the Warburg effect to symbiotic energy fuel exchange in cancer cells. Radiother Oncol 92: 329-333.

41. DeBerardinis RJ, Cheng T (2010) Q's next: the diverse functions of glutamine in metabolism, cell biology and cancer. Oncogene 29: 313-324.
42. Koukourakis MI, Giatromanolaki A, Harris AL, Sivridis E (2006) Comparison of metabolic pathways between cancer cells and stromal cells in colorectal carcinomas: a metabolic survival role for tumor-associated stroma. Cancer Res 66: $632-637$.

43. Julien C, Payen JF, Tropres I, Farion R, Grillon E, et al. (2004) Assessment of vascular reactivity in rat brain glioma by measuring regional blood volume during graded hypoxic hypoxia. Br J Cancer 91: 374-380.

44. Rauch C, Pluen A, Foster N, Loughna P, Mobasheri A, et al. (2010) On some aspects of the thermodynamic of membrane recycling mediated by fluid phase endocytosis: evaluation of published data and perspectives. Cell Biochem Biophys 56: 73-90.

45. Paulusma CC, Oude Elferink RP (2005) The type 4 subfamily of P-type ATPases, putative aminophospholipid translocases with a role in human disease. Biochim Biophys Acta 1741: 11-24

46. Wilbers KH, Haest CW, von Benthem M, Deuticke B (1979) Influence of enzymatic phospholipid cleavage on the permeability of the erythrocyte membrane. II. Protein-mediated transfer of monosaccharides and anions. Biochim Biophys Acta 554: 400-409.

47. Mahon PC, Hirota K, Semenza GL (2001) FIH-1: a novel protein that interacts with HIF-1alpha and VHL to mediate repression of HIF-1 transcriptional activity. Genes Dev 15: 2675-2686.

48. Elvidge GP, Glenny L, Appelhoff RJ, Ratcliffe PJ, Ragoussis J, et al. (2006) Concordant regulation of gene expression by hypoxia and 2-oxoglutaratedependent dioxygenase inhibition: the role of HIF-1alpha, HIF-2alpha, and other pathways. J Biol Chem 281: 15215-15226.

49. Semenza GL (2009) Involvement of oxygen-sensing pathways in physiologic and pathologic erythropoiesis. Blood 114: 2015-2019.

50. Carmeliet P, Dor Y, Herbert JM, Fukumura D, Brusselmans K, et al. (1998 Role of HIF-1alpha in hypoxia-mediated apoptosis, cell proliferation and tumour angiogenesis. Nature 394: 485-490.

51. Iyer NV, Kotch LE, Agani F, Leung SW, Laughner E, et al. (1998) Cellular and developmental control of $\mathrm{O} 2$ homeostasis by hypoxia-inducible factor 1 alpha. Genes Dev 12: 149-162.

52. Ryan HE, Lo J, Johnson RS (1998) HIF-1 alpha is required for solid tumor formation and embryonic vascularization. EMBO J 17: 3005-3015.

53. Le Bras A, Lionneton F, Mattot V, Lelievre E, Caetano B, et al. (2007) HIF2alpha specifically activates the VE-cadherin promoter independently of hypoxia and in synergy with Ets-1 through two essential ETS-binding sites. Oncogene 26: 7480-7489.

54. Bertram JS, Janik P (1980) Establishment of a cloned line of Lewis Lung Carcinoma cells adapted to cell culture. Cancer Lett 11: 63-73.

55. Taper HS, Woolley GW, Teller MN, Lardis MP (1966) A new transplantable mouse liver tumor of spontaneous origin. Cancer Res 26: 143-148.

56. Martinive P, De Wever J, Bouzin C, Baudelet C, Sonveaux P, et al. (2006) Reversal of temporal and spatial heterogeneities in tumor perfusion identifies the tumor vascular tone as a tunable variable to improve drug delivery. Mol Cancer Ther 5: $1620-1627$.

57. Diepart C, Verrax J, Calderon PB, Feron O, Jordan BF, et al. (2010) Comparison of methods for measuring oxygen consumption in tumor cells in vitro. Anal Biochem 396: 250-256.

58. Sonveaux P, Brouet A, Havaux X, Gregoire V, Dessy C, et al. (2003) Irradiation-induced angiogenesis through the up-regulation of the nitric oxide pathway: implications for tumor radiotherapy. Cancer Res 63: 1012-1019.

59. Feron O, Belhassen L, Kobzik L, Smith TW, Kelly RA, et al. (1996) Endothelial nitric oxide synthase targeting to caveolae. Specific interactions with caveolin isoforms in cardiac myocytes and endothelial cells. J Biol Chem 271: 22810-22814.

60. Quintero M, Colombo SL, Godfrey A, Moncada S (2006) Mitochondria as signaling organelles in the vascular endothelium. Proc Natl Acad Sci U S A 103: 5379-5384.

61. Bouzin C, Brouet A, De Vriese J, DeWever J, Feron O (2007) Effects of vascular endothelial growth factor on the lymphocyte-endothelium interactions: identification of caveolin-1 and nitric oxide as control points of endothelial cell anergy. J Immunol 178: 1505-1511.

62. Dimmeler S, Dernbach E, Zeiher AM (2000) Phosphorylation of the endothelial nitric oxide synthase at ser-1177 is required for VEGF-induced endothelial cell migration. FEBS Lett 477: 258-262.

63. Brouet A, Sonveaux P, Dessy C, Moniotte S, Balligand JL, et al. (2001) Hsp90 and caveolin are key targets for the proangiogenic nitric oxide-mediated effects of statins. Circ Res 89: 866-873.

64. Del Prete E, Lutz TA, Scharrer E (2004) Inhibition of glucose oxidation by alpha-cyano-4-hydroxycinnamic acid stimulates feeding in rats. Physiol Behav 80: 489-498.

65. Dewhirst MW, Kimura H, Rehmus SW, Braun RD, Papahadjopoulos D, et al. (1996) Microvascular studies on the origins of perfusion-limited hypoxia. Br J Cancer Suppl 27: S247-S251.

66. Sonveaux P, Dessy C, Brouet A, Jordan BF, Gregoire V, et al. (2002) Modulation of the tumor vasculature functionality by ionizing radiation accounts for tumor radiosensitization and promotes gene delivery. FASEB J 16: 1979-1981. 